\title{
Dynamics on Seasonal Variability of EKE Associated with TIWs in the Eastern Equatorial Pacific Ocean
}

\author{
MINYANG WANG AND YAN DU \\ State Key Laboratory of Tropical Oceanography, South China Sea Institute of Oceanology, Chinese Academy of Sciences, \\ Guangzhou, and University of Chinese Academy of Sciences, Beijing, China \\ Bo QIU \\ Department of Oceanography, University of Hawai'i at Mānoa, Honolulu, Hawaii \\ SHANG-PING XIE \\ Scripps Institution of Oceanography, University of California, San Diego, La Jolla, California, and \\ Physical Oceanography Laboratory/CIMST, Ocean University of China, and Qingdao \\ National Laboratory for Marine Science and Technology, Qingdao, China \\ MING FENG \\ CSIRO Oceans and Atmosphere, Crawley, Western Australia, Australia.
}

(Manuscript received 9 August 2018, in final form 5 March 2019)

\begin{abstract}
Energetic mesoscale eddies (vortices) associated with tropical instability waves (TIWs) exist in the eastern equatorial Pacific Ocean between $0^{\circ}$ and $8^{\circ} \mathrm{N}$. This study examines the seasonal variations in eddy kinetic energy (EKE) of TIWs using in situ and satellite observations and elucidates the underlying dynamical mechanisms. The results reveal that the cross-equatorial southerly winds are key to sustaining the high-level EKE (up to $\sim 600 \mathrm{~cm}^{2} \mathrm{~s}^{-2}$ ) from boreal summer to winter in $0^{\circ}-6^{\circ} \mathrm{N}$ and $155^{\circ}-110^{\circ} \mathrm{W}$. Because of the $\beta$ effect and the surface wind divergence, the southerly winds generate anticyclonic wind curls north of the equator that intensify the sea surface temperature (SST) fronts and force the downwelling annual Rossby waves. The resultant sea surface height ridge induces strong horizontal current shears between $0^{\circ}$ and $5^{\circ} \mathrm{N}$. The intensified current shears and SST fronts generate EKE via barotropic and baroclinic instabilities, respectively. To the extent that the seasonal migration of a northward-displaced intertropical convergence zone intensifies the southerly winds north of, but not south of, the equator, our study suggests that the climatic asymmetry is important for the oceanic eddy generations in the eastern equatorial Pacific Ocean—a result with important implications for coupled climate simulation/prediction.
\end{abstract}

\section{Introduction}

Energetic mesoscale perturbations of sea surface height, currents, and temperature, which are called tropical instability waves (TIWs), exist in the eastern equatorial Pacific Ocean (Duing et al. 1975; Legeckis 1977; Wyrtki 1978; Miller et al. 1985), with periods and wavelengths on the orders of 30 days and $1000 \mathrm{~km}$, respectively (Qiao and Weisberg 1995; Farrar 2011). These scales are distinct from the 100 days and $100 \mathrm{~km}$ for the midlatitude mesoscale eddies (Chelton et al. 2011). Previous

Corresponding author: Yan Du, duyan@scsio.ac.cn observations and numerical studies have demonstrated that these perturbations were unstable equatorially trapped 33-day Rossby waves (Lyman et al. 2005; Willett et al. 2006) and anticyclonic eddies/vortices (Fig. 1a; Kennan and Flament 2000; Zheng et al. 2016) near $5^{\circ} \mathrm{N}$, and unstable 17-day Yanai waves (Fig. 1c; Lyman et al. 2007) near the equator induced by the barotropic and baroclinic instabilities in the presence of background zonal currents (Philander 1978; Johnson and McPhaden 1993; Yu et al. 1995). These mesoscale activities are evident with high values of eddy kinetic energy (EKE) in the eastern equatorial Pacific Ocean. They have significant influences on the mean energy and heat balance of the equatorial 

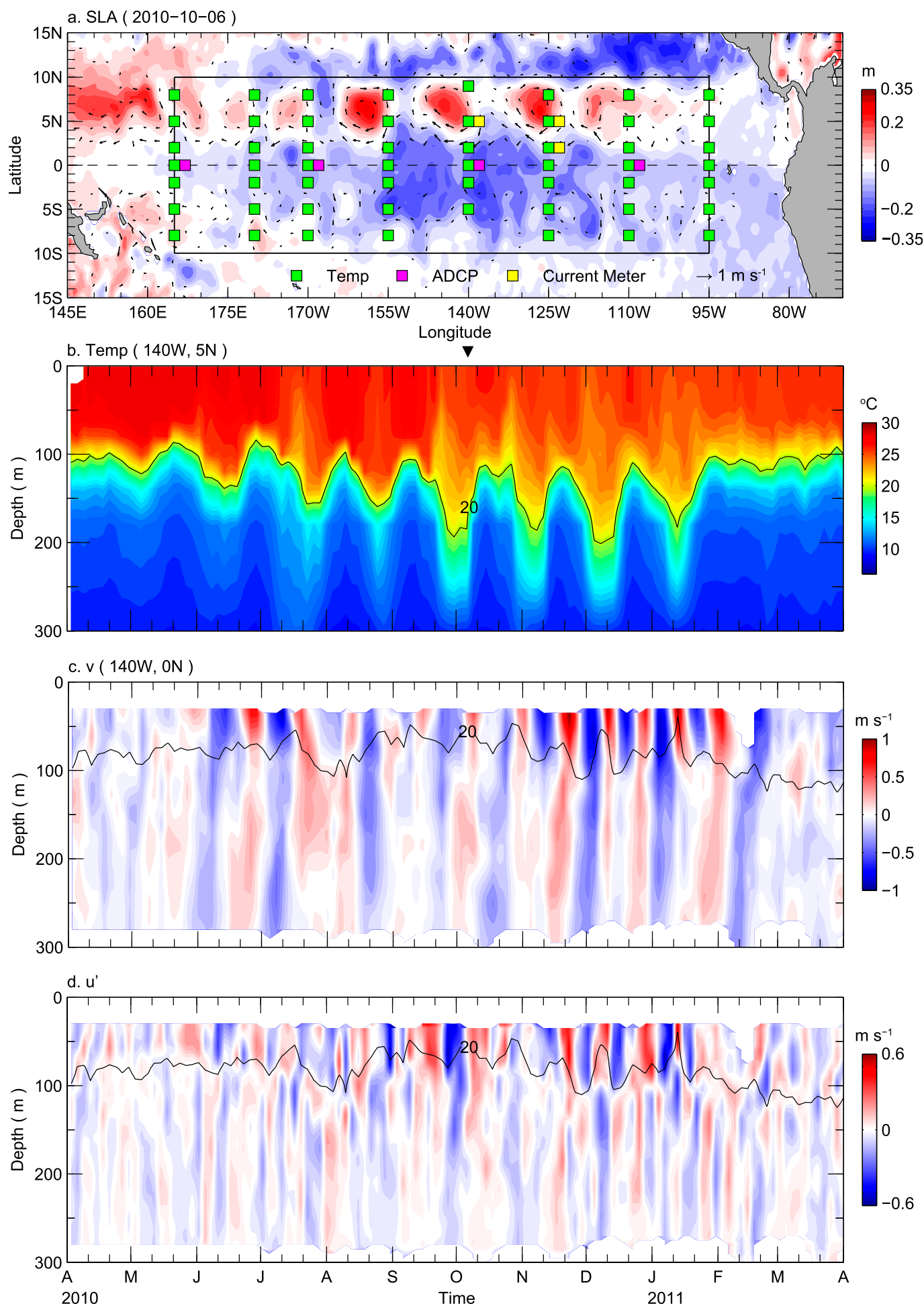

FIG. 1. (a) A snapshot of SSH anomaly (shading) and geostrophic velocity anomaly (arrows) on 6 Oct 2010 in the central and eastern equatorial Pacific from AVISO. The big black-outlined box represents the region of our interest. The green, magenta, and yellow squares denote the locations of temperature, ADCP, and current-meter moorings, respectively. One-year episodes of mooring observations during April 2010-April 2011 are shown for (b) temperature at $5^{\circ} \mathrm{N}, 140^{\circ} \mathrm{W}$ and (c) meridional and (d) zonal velocities at $0^{\circ}, 140^{\circ} \mathrm{W}$, where the zonal velocity is the anomaly after removing the 33-day running mean. The black curves in (b)-(d) denote the $20^{\circ} \mathrm{C}$ isotherm regarded as the thermocline. 
cold tongue as feedbacks on the ocean circulation (Semtner and Holland 1980; Brown et al. 2010), sea surface temperature (SST) (Hansen and Paul 1984; Wang and McPhaden 1999; Baturin and Niiler 1997; Jochum et al. 2007), and the atmospheric boundary layer (Xie et al. 1998; Chelton et al. 2001; Small et al. 2008).

Early satellite and in situ observations showed that TIWs often developed in the boreal ("boreal" is implicit hereinafter) summer and peaked in the autumn and winter (Wyrtki 1978; Legeckis et al. 1983). The EKE budget analyses using in situ observations (Luther and Johnson 1990; Qiao and Weisberg 1998) suggested that the equatorial EKE was mainly transferred from the mean flow kinetic energy (MKE) in summer and autumn via barotropic instability, and from the available potential energy (APE) in winter via baroclinic instability. Many observational and numerical studies have confirmed that the barotropic and baroclinic instabilities were mainly attributed to the zonal current shears between the Equatorial Undercurrent (EUC), the South Equatorial Current (SEC) north of the equator (hereinafter SEC), and the North Equatorial Countercurrent (NECC) (Philander 1978; Cox 1980; Flament et al. 1996; Qiao and Weisberg 1998), and the sharp SST fronts north of the equator (Yu et al. 1995; Yu and Liu 2003), respectively. Hence, the variations of the equatorial zonal currents and the SST fronts are primary factors responsible for the EKE variability.

The equatorially trapped annual Rossby waves and Kelvin waves are able to modulate the intensity of TIWs through modifications to the background currents (Harrison and Giese 1988; Qiao and Weisberg 1998). A recent study has suggested that the TIWs kinetic energy can be intensified by the upwelling 60-day Kelvin waves through modifications to the background currents and the TIWs' Reynolds stresses (Holmes and Thomas 2016). Our recent study suggested that the EKE north of the equator was enhanced by the downwelling annual Rossby waves, using an eddy-resolving ocean general circulation model output (Wang et al. 2017). The annual Rossby waves and 60-day Kelvin waves are modulated by the wind stress forcing in the eastern Pacific and the atmosphere forcing of Madden-Julian oscillation or westerly wind bursts in the western equatorial Pacific (Eriksen et al. 1983; Johnson and McPhaden 1993; Kessler et al. 1995), respectively. The regional air-sea interaction can maintain the sharp SST fronts in the eastern north equatorial Pacific through the Ekman transports and surface heat fluxes (de Szoeke et al. 2007). Therefore, TIWs can be regulated by the regional air-sea interaction through modulations to the current shears and SST fronts. Here we investigate the relationship between the seasonality in EKE of TIWs and the reginal air-sea interaction. This is important for the coupled climate simulation because of the TIWs feedback on the large-scale ocean circulation and the atmosphere boundary layer in the eastern equatorial Pacific (Pezzi et al. 2004; Jochum et al. 2007; Small et al. 2009).

The cross-equatorial southerly winds prevail from summer to winter as the intertropical convergence zone (ITCZ) stays northward in the eastern equatorial Pacific. This meridional asymmetric air-sea coupling process involves the wind-evaporation-SST (WES) feedback (Xie and Philander 1994; Xie 1994). Here we propose that the seasonal EKE variability is related to the southerly winds from summer to winter. To test this hypothesis, we revisit the seasonal EKE variability using available observations, examine dynamic mechanisms associated with the southerly winds, and discuss the relationship between the regional air-sea interaction and TIWs. The paper is organized as follows. Section 2 describes the observations, and estimations of the EKE, EPE (eddy potential energy), and the barotropic and baroclinic conversion rates. Section 3 presents the mean states and seasonal variations of EKE, EPE, and the barotropic and baroclinic conversion rates. The dynamic processes governing the EKE seasonality are explored in section 4 . Summary and discussion are in section 5 .

\section{Data and method}

\section{a. Satellite observations}

Absolute dynamic topography (ADT) data for 19932016 are used to investigate off-equatorial EKE in this study. The ADT data are based on a merged product from multiple satellite missions [Hai Yang $2 A(H Y-2 A)$, Satellite with Argos and Altika (SARAL/ALtiKa), Cryosat-2, Ocean Surface Topography Mission (OSTM)/Jason-2, Jason-1, TOPEX/Poseidon, Envisat, Geosat Follow-On (GFO), and ERS-1 and -2], distributed by Archiving, Validation, and Interpretation of Satellite Oceanographic Data (AVISO) on a $1 / 4^{\circ} \times 1 / 4^{\circ}$ Mercator grid at a daily interval. Given that the spatial variability of the regional geoid is small, the ADT is referred to as sea surface height (SSH) in this study. Focused on the 1000-km scale and monthly TIWs signals near the equator, the data are linearly subsampled to $1 / 2^{\circ} \times 1 / 2^{\circ}$ and 3-day values. After removing the 24-yr mean SSH, a snapshot of SSH anomaly on 6 October 2010 is shown in Fig. 1a, where the blackoutlined box of $165^{\circ} \mathrm{E}-95^{\circ} \mathrm{W}$ and $10^{\circ} \mathrm{S}-10^{\circ} \mathrm{N}$ is the region of interest. The SSH records detect several strong anticyclonic eddies in the northern part of the region.

This study also uses sea surface wind velocity, SST, and rainfall data from satellite observations to analyze the regional air-sea interaction. They are the Institut 


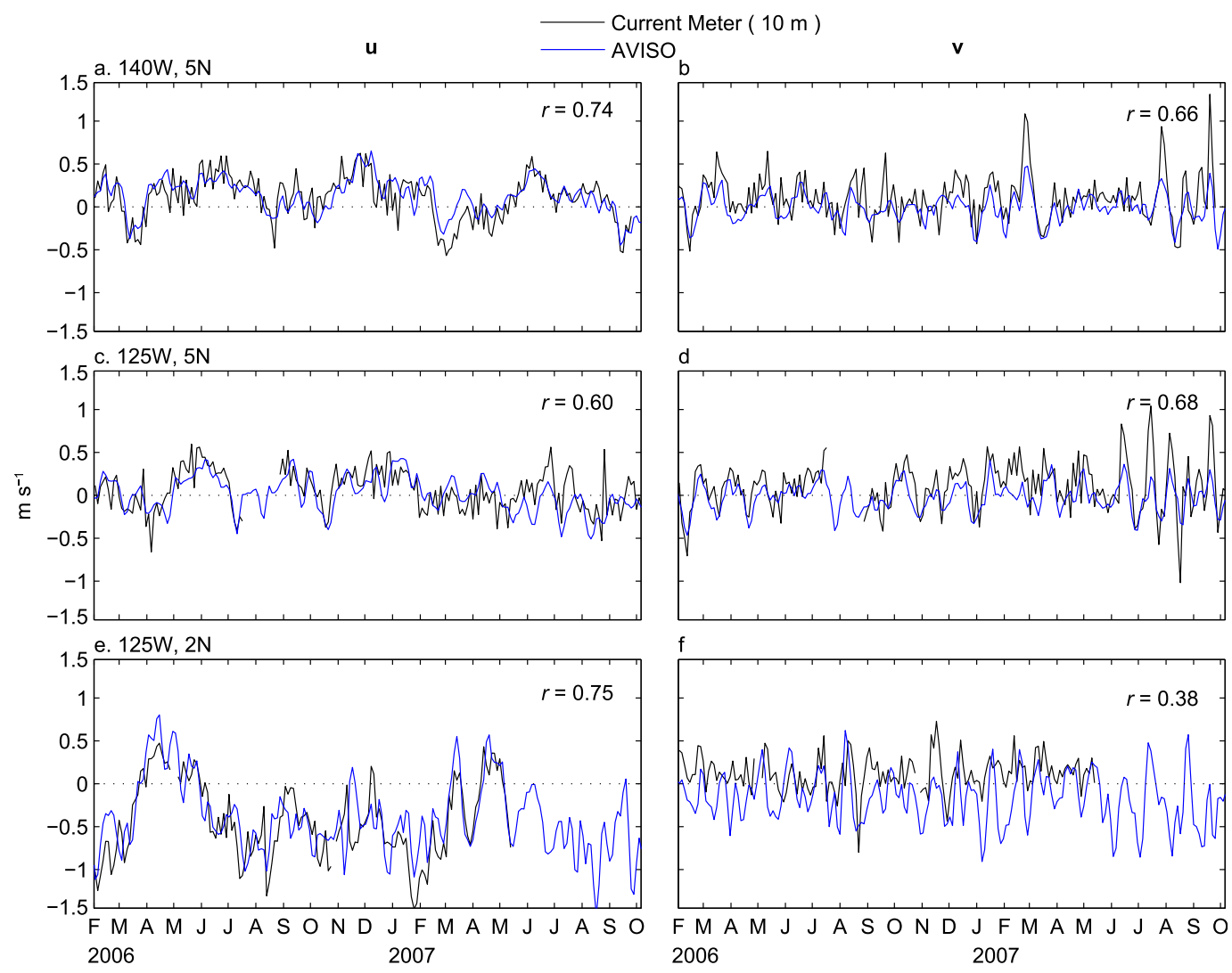

FIG. 2. Episodes of (left) zonal and (right) meridional velocities from AVISO (blue lines) and the $10 \mathrm{~m}$-depth current-meter measurements (black lines) during February 2006-October 2007 at three sites at (a),(b) $5^{\circ} \mathrm{N}, 140^{\circ} \mathrm{W}$; (c),(d) $5^{\circ} \mathrm{N}, 125^{\circ} \mathrm{W}$; and (e),(f) $2^{\circ} \mathrm{N}, 125^{\circ} \mathrm{W}$ (the three yellow squares in Fig. 1a). The $r$ value in (a)-(f) is the correlation coefficient between the black and blue lines, with all passing the Student's $t$ test at the $99 \%$ confidence level.

Français de Recherche pour l'Exploitation de la Mer (Ifremer) 6-hourly Long Time Series Satellite Surface Wind Analyses (hereinafter Ifremer), the NOAA Optimum Interpolation $14^{\circ} \times 1 / 4^{\circ}$ Daily SST blended with AVHRR data (OISST), and the TRMM Microwave Imager (TMI) product, respectively, all subsampled to $1 / 2^{\circ} \times 1 / 2^{\circ}$ and monthly values, and 3-day values only for SST data.

\section{b. In situ observations}

We use temperature and velocity measurements from the Tropical Atmosphere Ocean (TAO) array (McPhaden et al. 1998) to investigate the baroclinic instability and the equatorial subsurface EKE, respectively. The TAO array used here consists of 62 moorings: 55 Autonomous Temperature Line Acquisition System (ATLAS) moorings within $165^{\circ} \mathrm{E}-95^{\circ} \mathrm{W}, 8^{\circ} \mathrm{S}-9^{\circ} \mathrm{N} ; 4$ ADCP moorings on the equator; and 3 current-meter moorings at $\left(5^{\circ} \mathrm{N}, 140^{\circ} \mathrm{W}\right)$, $\left(5^{\circ} \mathrm{N}, 125^{\circ} \mathrm{W}\right)$, and $\left(2^{\circ} \mathrm{N}, 125^{\circ} \mathrm{W}\right)$, marked by colored boxes in Fig. 1a. All mooring data are available from the Pacific Marine Environmental Laboratory (PMEL).
The temperature data are daily values in 1993-2016 from 11 thermistors at depth of 1, 20, 40, 60, 80, 100, 120, $140,180,300$, and $500 \mathrm{~m}$. A $1-\mathrm{yr}$ episode of the temperature records at $5^{\circ} \mathrm{N}, 140^{\circ} \mathrm{W}$ during April 2010-April 2011 is shown in Fig. 1b, from which the 33-day TIWs perturbations can be clearly detected. Velocities from the ADCPs have a daily resolution from 1988 to 2016 and a regular grid with 5-m depth intervals. Episodes of the meridional and zonal velocities at $0^{\circ}, 140^{\circ} \mathrm{W}$ are shown in Figs. 1c and 1d, in which the 17-day TIWs perturbations (Lyman et al. 2007) are equally detectable. Gaps from 1 to 3 days, short with respect to the TIWs periods, are filled by linear interpolations, while longer gaps in the temperature and velocity records are unaltered. The ADCP data in the upper $35 \mathrm{~m}$ are excluded due to few records. All data are linearly subsampled to a 3-day time interval and interpolated to a $5 \mathrm{~m}$ depth interval.

Records from the three current meters are available during February 2006-October 2007 at the depth of $10 \mathrm{~m}$. They are subsampled to 3-day values to estimate 

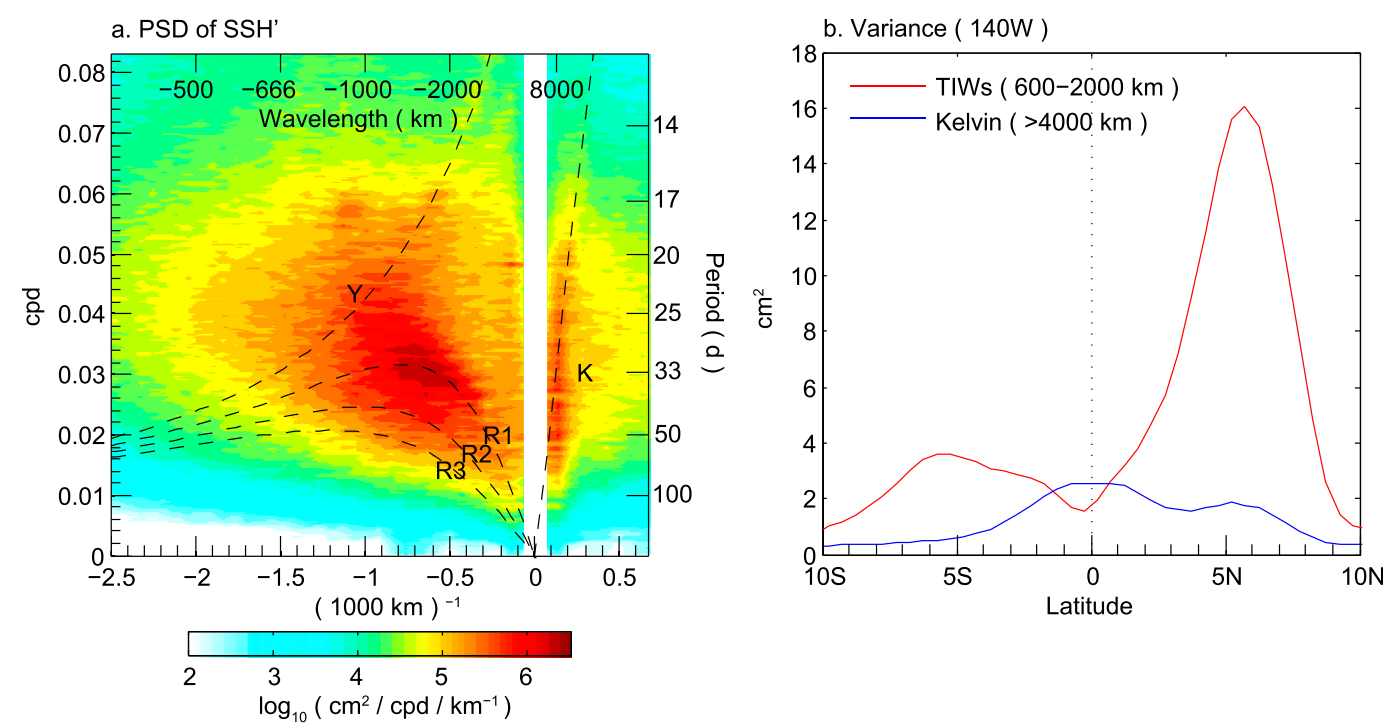

FIG. 3. (a) Zonal-wavelength-period power spectral density diagram of 33-day SSH anomaly in $165^{\circ} \mathrm{E}-95^{\circ} \mathrm{W}$ averaged between $8^{\circ} \mathrm{S}$ and $8^{\circ} \mathrm{N}$ (Farrar 2011). The five black dashed curves are the dispersion curves of linear equatorial waves (Matsuno 1966), with the phase velocity of long gravity wave at $c=2.8 \mathrm{~m} \mathrm{~s}^{-1}$. The Y, R1-3, and $\mathrm{K}$ are abbreviations for Yanai, Rossby, and Kelvin waves, respectively. (b) Variances of 33-day SSH anomaly zonally filtered at bands of 600-2000 km (TIWs; red curve) and $>4000 \mathrm{~km}$ (Kelvin waves; blue curve) at $140^{\circ} \mathrm{W}$.

the bias of the geostrophic velocities based on AVISO $\mathrm{SSH} 2^{\circ}$ away from the equator. The geostrophic velocities are given by $u=-g h_{y} /(\beta y)$ and $v=g h_{x} /(\beta y)$ on the equatorial $\beta$ plane, where $h$ is the SSH, $y$ is the distance northward from the equator, the subscripted variables denote partial differentiations, the gravity constant $g=9.8 \mathrm{~m} \mathrm{~s}^{-2}$, and the equatorial meridional gradient of the Coriolis parameter $\beta=2.3 \times 10^{-11} \mathrm{~s}^{-1} \mathrm{~m}^{-1}$. The estimated geostrophic velocities show good correlations with the 10-m-depth current-meter measurements, especially the zonal geostrophic components (Fig. 2, left panels). However, the amplitudes of perturbations in the meridional components show $39 \%$ weak biases at the two $5^{\circ} \mathrm{N}$ sites and a $50 \%$ strong bias at the $2^{\circ} \mathrm{N}$ site. The weak biases might result from the spatial smoothing in the AVISO product and the strong bias might from the large Rossby number near the equator (Wang et al. 2018). We exclude the region within $2^{\circ}$ to the equator in the following calculation of EKE based on AVISO. Although the geostrophic velocity biases are large near the equator, the EKE from AVISO is, nevertheless, useful to present the large-scale variability of TIWs.

\section{c. EKE, EPE, and barotropic/baroclinic energy conversion rates}

The mesoscale perturbations associated with TIWs or vortices have periods and wavelengths in ranges of 16-40 days and 600-2000 km, respectively (Qiao and Weisberg 1995; Kennan and Flament 2000; Farrar 2011). Since the mooring observations measure the dynamic processes in temporal rather than in spatial scope, we define the mesoscale perturbations in the period of 6-66 days based on the spectrum analysis (Fig. 3a). The perturbations mainly consist of TIWs $(600-2000 \mathrm{~km})$ and parts of the intraseasonal Kelvin waves (basin scale of $\sim 8000 \mathrm{~km}$ ), whose variances are at $\sim 78 \%$ and $\sim 20 \%$ of the total 6-66 days SSH anomalies, respectively (Fig. 3b). The wavelet power diagrams (Mallat 1999; Lyman et al. 2005) show that the 33-day TIWs are dominant in the variances of the $\mathrm{SSH}$ and temperature anomalies near $5^{\circ} \mathrm{N}$ (Figs. 4a-d). The 17-day TIWs are shown to dominate the equatorial EKE, especially in the meridional velocities (Figs. 4e-h), although the Kelvin waves are stronger than TIWs in SSH within about $2^{\circ}$ of the equator (Fig. 3b). The 33- and 17-day TIWs energies both stay in high values from July to January, except that the 17-day TIWs energy has an extreme peak in December. The equatorial 17-day TIWs are also observed in the other two ADCP moorings at $0^{\circ}, 170^{\circ} \mathrm{W}$ and $0^{\circ}, 110^{\circ} \mathrm{W}$ but with periods varying between 16 and 23 days (Qiao and Weisberg 1995; Zhou and Boyd 2009), and in the temperature moorings at $2^{\circ} \mathrm{N}$ and $2^{\circ} \mathrm{S}$ (Lyman et al. 2007). Therefore, the EKE in this study is dominated by the 33-day TIWs near $5^{\circ} \mathrm{N}$ and the 17-day TIWs within about $2^{\circ}$ of the equator.

To investigate the processes responsible for the EKE seasonality, we evaluate the eddy energy conversion rates with the use of AVISO and mooring observations. EKE and EPE in the TIWs area can be converted from MKE and APE via barotropic conversion rate (BTR) and baroclinic conversion rate (BCR), respectively (Qiao and 

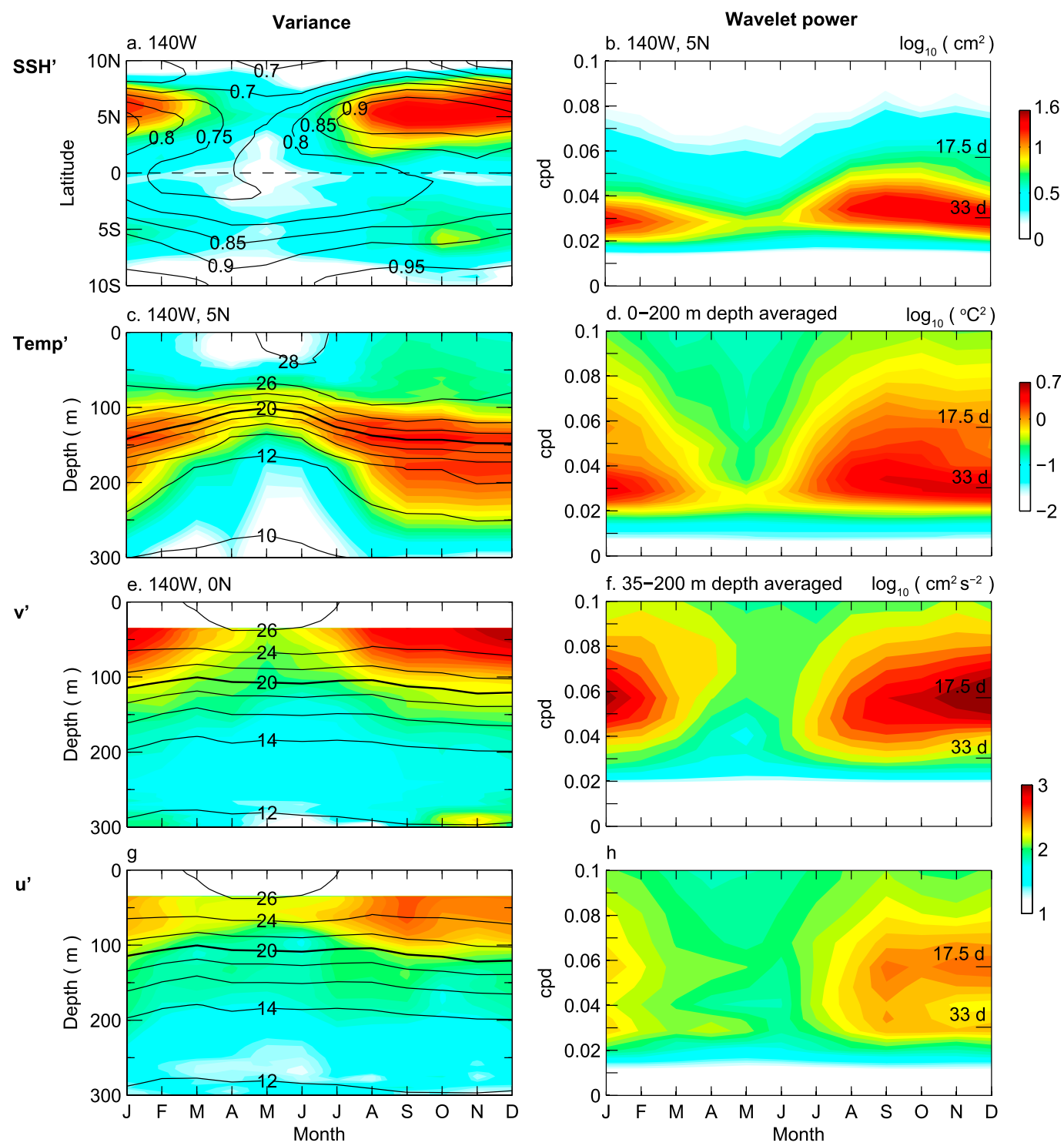

FIG. 4. Seasonal variations of (left) variances and (right) wavelet powers in 33-day anomalies of (a),(b) SSH at $140^{\circ} \mathrm{W} ;(\mathrm{c}),(\mathrm{d})$ temperature at $5^{\circ} \mathrm{N}, 140^{\circ} \mathrm{W}$; and (e),(f) meridional and (g),(h) zonal velocities at $0^{\circ}, 140^{\circ} \mathrm{W}$. Black contours in (a) and in (c), (e), (g) represent the seasonal mean $\mathrm{SSH}(\mathrm{m})$ and isotherms $\left({ }^{\circ} \mathrm{C}\right)$, respectively.

Weisberg 1998). Additionally, EKE can gain energy from EPE through positive vertical buoyancy work $\left(-g \rho^{\prime} w^{\prime} / \rho_{0}\right)$, where $w$ is the vertical velocity, $\rho$ is the density, and $\rho_{0}=1024 \mathrm{~kg} \mathrm{~m}^{-3}$. Because of the lack of vertical velocity measurements, we estimate BCR and EPE instead to analyze the energy conversion between EKE and EPE. The EKE, EPE, BTR, and BCR are given on the Boussinesq approximation by

$$
\begin{aligned}
& \mathrm{EKE}=\frac{1}{2}\left(\overline{u^{12}}+\overline{v^{12}}\right), \\
& \mathrm{EPE}=\frac{1}{2} \frac{g^{2}}{N^{2}} \overline{\varrho^{12}},
\end{aligned}
$$

$$
\begin{aligned}
& \mathrm{BTR}=\underbrace{-U_{x} \overline{u^{\prime} u^{\prime}}}_{\mathrm{U}_{\mathrm{x}} \mathrm{P}}-\underbrace{U_{y} \overline{u^{\prime} v^{\prime}}-V_{\mathrm{V}_{\mathrm{x}} \mathrm{P}}^{\overline{u^{\prime} v^{\prime}}}-V_{y} \overline{v^{\prime} v^{\prime}}}_{\mathrm{U}_{\mathrm{y}} \mathrm{P}}, \text { and } \\
& \mathrm{BCR}=\underbrace{-\frac{g \bar{\varrho}_{x}}{N} \frac{g \overline{Q^{\prime} u^{\prime}}}{N}}_{\mathrm{F}_{\mathrm{y}} \mathrm{P}} \underbrace{-\frac{g \bar{\varrho}_{y}}{N} \frac{g \overline{\varrho^{\prime} v^{\prime}}}{N}}_{\mathrm{F}_{\mathrm{y}} \mathrm{P}},
\end{aligned}
$$

where $u$ and $v$ are the zonal and meridional velocities. The surface velocities $2^{\circ}$ away from the equator are calculated from AVISO SSH (section 2b), the subsurface velocities on the equator are from the ADCP measurements, and the density ratio $\varrho=\rho / \rho_{0}$ is estimated from 

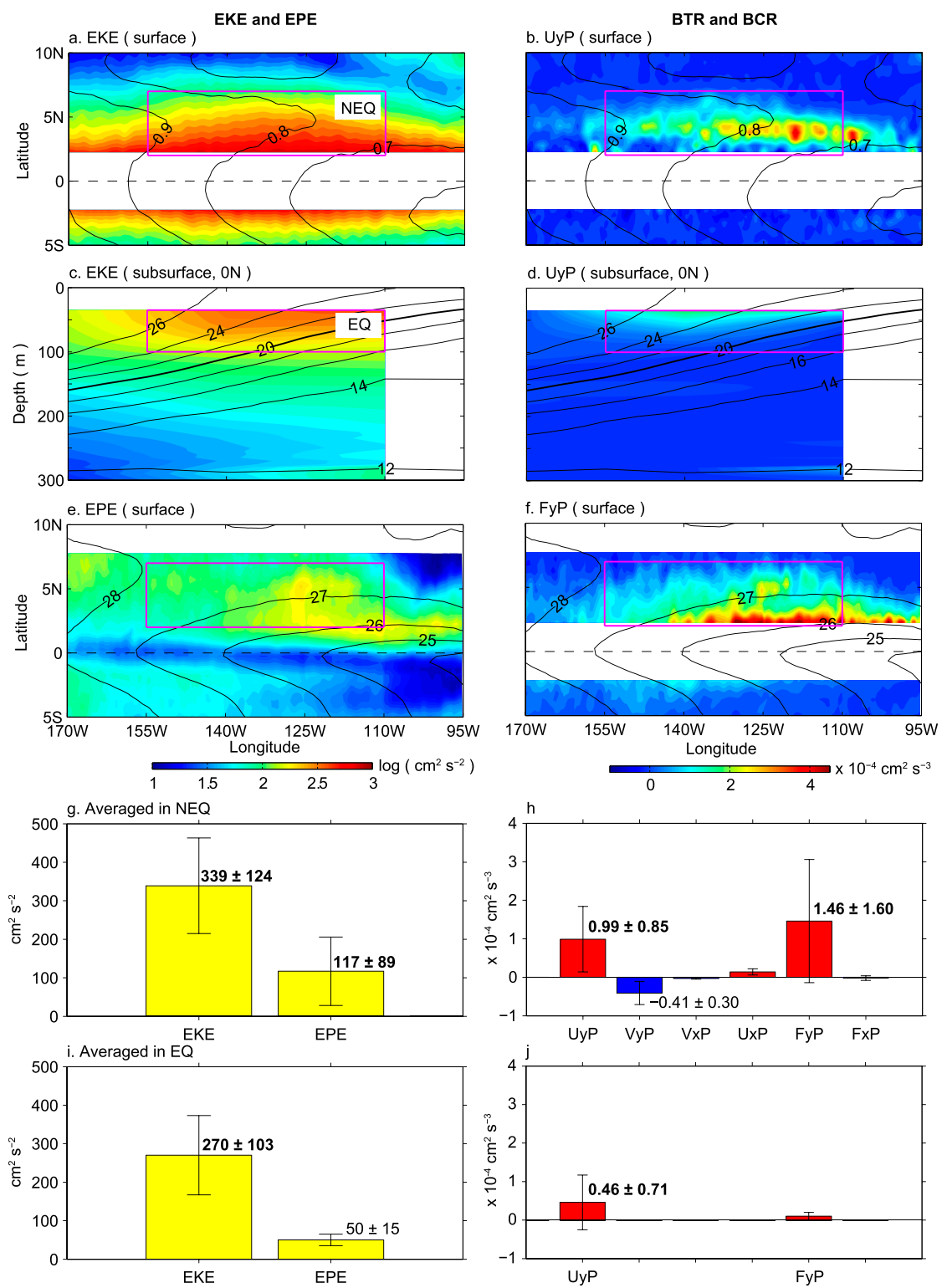

FIG. 5. Mean (left) EKE and EPE and (right) BTR and BCR terms: (a),(b) surface EKE and $\mathrm{U}_{\mathrm{y}} \mathrm{P}$ with $\mathrm{SSH}$ (contours; $\mathrm{m}$ ) overlaid; (c),(d) $0^{\circ} \mathrm{EKE}$ and $\mathrm{U}_{\mathrm{y}} \mathrm{P}$ with isotherms (contours; $\left.{ }^{\circ} \mathrm{C}\right)$; (e),(f) surface EPE and $\mathrm{F}_{\mathrm{y}} \mathrm{P}$ with SST (contours; $\left.{ }^{\circ} \mathrm{C}\right) ;(\mathrm{g}),(\mathrm{h})$ averaged in Slice NEQ; and (i),(j) averaged in Slice EQ. Slices NEQ and EQ are denoted by the magenta boxes in (a) and (c) of $155^{\circ}-110^{\circ} \mathrm{W}, 2^{\circ}-7^{\circ} \mathrm{N}$ at the surface and $155^{\circ}-110^{\circ} \mathrm{W}, 0^{\circ}$ vertically over $35-100 \mathrm{~m}$, respectively. The error bars in $(\mathrm{g})-(\mathrm{j})$ represent their seasonality, with the values of mean plus/minus amplitude displayed next to them.

the OISST and mooring temperatures (appendix A). The buoyancy frequency $N=\left(-g \bar{\varrho}_{z}\right)^{1 / 2}$. The capital letters and bars denote the 33-day running means, and the primes denote the deviations of individual variables about their running means.

Positive (negative) values of BTR and BCR act to increase (decrease) EKE and EPE, respectively. The $U_{x} P$, $\mathrm{U}_{\mathrm{y}} \mathrm{P}, \mathrm{V}_{\mathrm{x}} \mathrm{P}$, and $\mathrm{V}_{\mathrm{y}} \mathrm{P}$ labels denote the productions of EKE through the current shears of $U_{x}, U_{y}, V_{x}$, and $V_{y}$, respectively. The $\mathrm{F}_{\mathrm{x}} \mathrm{P}$ and $\mathrm{F}_{\mathrm{y}} \mathrm{P}$ labels denote the productions of EPE through the buoyancy fronts of $F_{x}=g \bar{\varrho}_{x} / N$ and $F_{y}=g \bar{\varrho}_{y} / N$. In the equation of BTR [Eq. (3)], we have omitted the vertical shear productions of

$$
\underbrace{-U_{z} \overline{u^{\prime} w^{\prime}}}_{\mathrm{U}_{\mathrm{z}} \mathrm{P}} \text { and } \underbrace{-V_{z} \overline{v^{\prime} w^{\prime}}}_{\mathrm{V}_{\mathrm{z}} \mathrm{P}}
$$




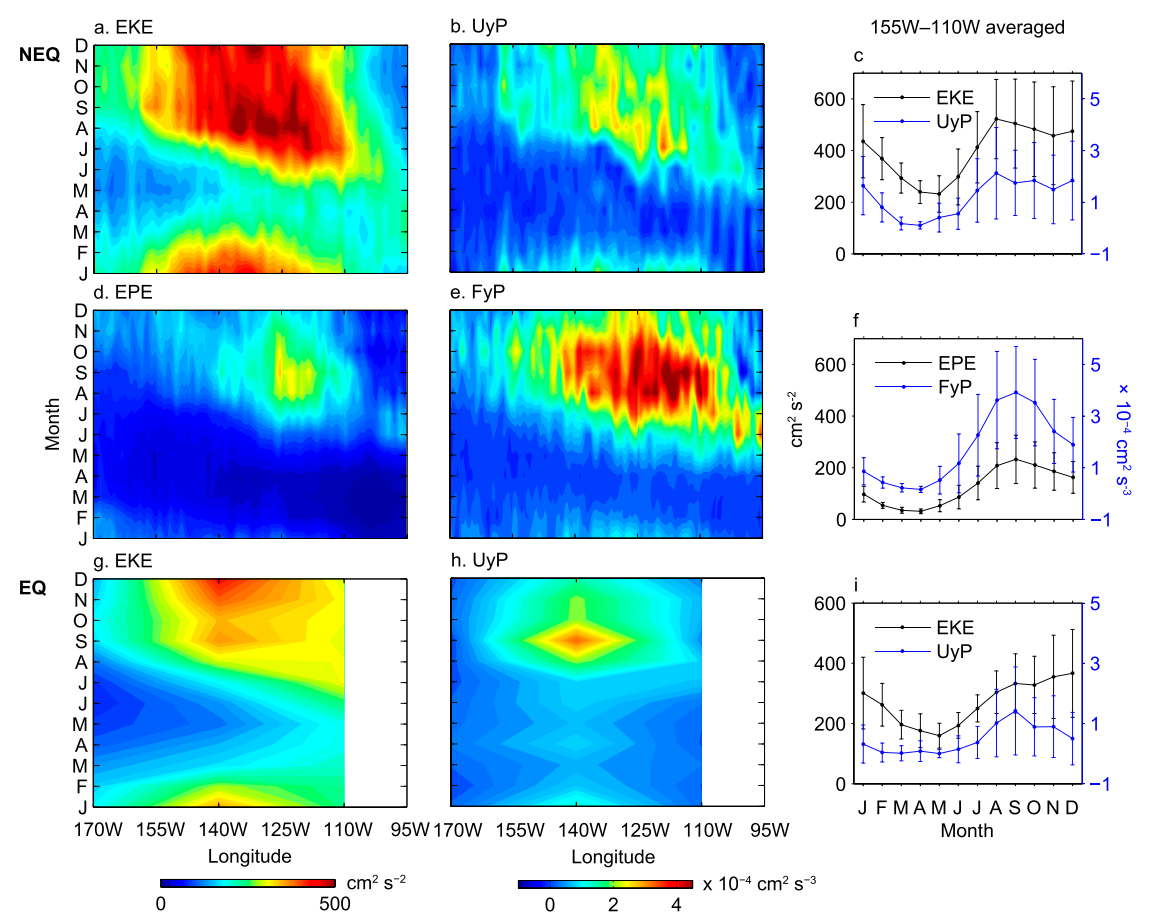

FIG. 6. Seasonal variations of (left) EKE and EPE and (center) $U_{\mathrm{y}} \mathrm{P}$ and $\mathrm{F}_{\mathrm{y}} \mathrm{P}$, along with (right) their seasonal series, (a),(b),(d),(e) Averaged between $2^{\circ}$ and $7^{\circ} \mathrm{N}$ at the surface; $(\mathrm{g}),(\mathrm{h})$ at $0^{\circ}$, averaged over $35-100 \mathrm{~m}$; and (c),(f),(i) averaged between $155^{\circ}$ and $110^{\circ} \mathrm{W}$. The error bars in (c), (f), and (i) denote their interannual variability.

because of the lack of vertical velocity. In the EKE budget presented by Holmes and Thomas (2016) using an eddy-resolving simulation (Fig. 3 in their paper), the $\mathrm{U}_{\mathrm{z}} \mathrm{P}$ and $\mathrm{V}_{\mathrm{z}} \mathrm{P}$ were weak near the surface because of the weak vertical velocities there. In the subsurface, the $\mathrm{U}_{\mathrm{z}} \mathrm{P}$ and $\mathrm{V}_{\mathrm{z}} \mathrm{P}$ were positive as energy sources to EKE, both of which were weaker than the $U_{y} P$. In addition to the local EKE generations via barotropic and baroclinic instabilities, EKE can be redistributed through pressure works (Cox 1980; Masina et al. 1999; Holmes and Thomas 2016). In this study, we only consider the local energy conversions. On the equator, we only estimate $\mathrm{U}_{\mathrm{y}} \mathrm{P}$ and $\mathrm{F}_{\mathrm{y}} \mathrm{P}$ based on mooring data and omit other terms in Eqs. (3) and (4) because of the small effects of $x$-derivative terms. Since there is no ADCP moorings off the equator, the zonal geostrophic velocity $U_{g}(y)$ derived from the $\mathrm{SSH}$ and mooring temperature is alternatively used to estimate $U_{y}$ on the equator (appendix B).

\section{Results}

\section{a. Mean states of EKE, EPE, BTR, and BCR}

The mean EKE exhibits high values at the surface within $155^{\circ}-110^{\circ} \mathrm{W}, 3^{\circ} \mathrm{S}-7^{\circ} \mathrm{N}$ (Fig. 5a) and in the upper
$100 \mathrm{~m}$ along the equator (Fig. 5c). We focus on and define the northern equatorial and equatorial EKE regions as Slice NEQ (north of equator) within $155^{\circ}-110^{\circ} \mathrm{W}$, $2^{\circ}-7^{\circ} \mathrm{N}$ at the surface and Slice EQ (equator) within $0{ }^{\circ}$ $155^{\circ}-110^{\circ} \mathrm{W}$ vertically $35-100 \mathrm{~m}$, respectively. The mean NEQ and EQ EKE are $339 \mathrm{~cm}^{2} \mathrm{~s}^{-2}$ and $270 \mathrm{~cm}^{2} \mathrm{~s}^{-2}$ with the large seasonality of amplitude 124 and $103 \mathrm{~cm}^{2} \mathrm{~s}^{-2}$ (Figs. 5g,i), which indicate the 33-day TIWs near $5^{\circ} \mathrm{N}$ and the 17-day TIWs on the equator, respectively (Fig. 4). The mean EPE peaks at $2^{\circ}$ and $5^{\circ} \mathrm{N}$ at the surface (Fig. 5e, where the subsurface EPE is weak and not shown).

In the NEQ region, the $\mathrm{U}_{\mathrm{y}} \mathrm{P}$ and $\mathrm{F}_{\mathrm{y}} \mathrm{P}$ are two dominant energy sources with mean values of $0.99 \times 10^{-4}$ and $1.46 \times 10^{-4} \mathrm{~cm}^{2} \mathrm{~s}^{-3}$, respectively, and exhibit large seasonality (Fig. 5h). The positive $\mathrm{U}_{\mathrm{y}} \mathrm{P}$ and $\mathrm{F}_{\mathrm{y}} \mathrm{P}$ suggest that the kinetic and potential energies are converted from MKE and APE to EKE and EPE through current shears $U_{y}$ and buoyancy fronts $F_{y}$, respectively. The $\mathrm{EPE}$ is much weaker than EKE while the $\mathrm{F}_{\mathrm{y}} \mathrm{P}$ is larger than $U_{y} P$, which implies that the potential energy might has been converted from EPE to EKE via positive vertical buoyancy works (Masina et al. 1999; Holmes and Thomas 2016; Wang et al. 2017). In the EQ region, the $\mathrm{U}_{\mathrm{y}} \mathrm{P}$ is positive about $0.46 \times 10^{-4} \mathrm{~cm}^{2} \mathrm{~s}^{-3}$ (Fig. $5 \mathrm{j}$ ). The $\mathrm{F}_{\mathrm{y}} \mathrm{P}$ is weak because of the weak meridional 
temperature gradients in the equatorial subsurface (Fig. B1). In conclusion, the $\mathrm{U}_{\mathrm{y}} \mathrm{P}$ is an important energy source for EKE in both NEQ and EQ regions, and the conversion from EPE to EKE might happen north of the equator because of the strong BCR there, which are coincident with previous studies (Cox 1980; Masina et al. 1999; Qiao and Weisberg 1998; Holmes and Thomas 2016; Wang et al. 2017).

\section{b. Seasonal variations of EKE, EPE, $U_{y} P$, and $F_{y} P$}

Averaged between $2^{\circ}$ and $7^{\circ} \mathrm{N}$, the EKE stays high in the second half of year and extends westward from June $\left(110^{\circ} \mathrm{W}\right)$ to December $\left(155^{\circ} \mathrm{W}\right)$, and so does the EPE (Figs. 6a,d). The seasonal variations of NEQ EKE and EPE are in phase with the $\mathrm{U}_{\mathrm{y}} \mathrm{P}$ and $\mathrm{F}_{\mathrm{y}} \mathrm{P}$ (Figs. 6b,c,e,f), respectively. This indicates that the EKE and EPE seasonality are predominantly related to the local energy conversions of $\mathrm{U}_{\mathrm{y}} \mathrm{P}$ and $\mathrm{F}_{\mathrm{y}} \mathrm{P}$, respectively, and the conversion from EPE to EKE might happen when the $\mathrm{F}_{\mathrm{y}} \mathrm{P}$ is strong during JulyDecember (Fig. 6e). The interannual variation of NEQ EKE (EPE) in 1993-2016 is in phase with the $\mathrm{U}_{\mathrm{y}} \mathrm{P}\left(\mathrm{F}_{\mathrm{y}} \mathrm{P}\right)$ (Figs. 7a,b), except that the EKE lags the $\mathrm{U}_{\mathrm{y}} \mathrm{P}$ by about 6 days. In the EKE budget equation (Qiao and Weisberg 1998), the time rate of EKE is in an order of magnitude lower than the conversion terms (figure not shown). For the large-scale variability, the energy sources keep in balance with the sinks, which are proportional to the EKE magnitude. Therefore, the EKE instead of the time rate of EKE is in phase with the $\mathrm{U}_{\mathrm{y}} \mathrm{P}$.

Averaged over depth of $35-100 \mathrm{~m}$, the EQ EKE develops from September and peaks in December (Fig. 6g), whereas the $\mathrm{U}_{\mathrm{y}} \mathrm{P}$ peaks in September (Fig. 6h). The interannual variation of EQ EKE is in phase with the $\mathrm{U}_{\mathrm{y}} \mathrm{P}$ (Fig. 7c). In other words, the EQ EKE seasonality is related to the $\mathrm{U}_{\mathrm{y}} \mathrm{P}$ except in winter when the 17-day TIWs are strongest (Fig. 4f). The $U_{z}$, based on ADCP, displays the same annual cycle as $\mathrm{U}_{\mathrm{y}} \mathrm{P}$ (figure not shown), which suggests that $\mathrm{U}_{\mathrm{z}} \mathrm{P}$ cannot explain the EQ EKE in winter either. The reason for the EQ EKE peaking in winter might be the nonlinear effects of 60 -day Kelvin waves and/or the 33-day TIWs at $5^{\circ} \mathrm{N}$ (Zhou and Boyd 2009). Holmes and Thomas (2016) has shown that the downwelling 60-day Kelvin waves can reduce the volume-integrated TIWs kinetic energy by $38 \%$, and the upwelling Kelvin waves can intensify that by $42 \%$. Thus, the nonlinear effects of the Kelvin waves might increase the EQ EKE, especially in winter when the Kelvin waves are strongest (Kessler et al. 1995). However, the effects of Kelvin waves or 33-day TIWs on the seasonality of 17-day TIWs need specific investigations.
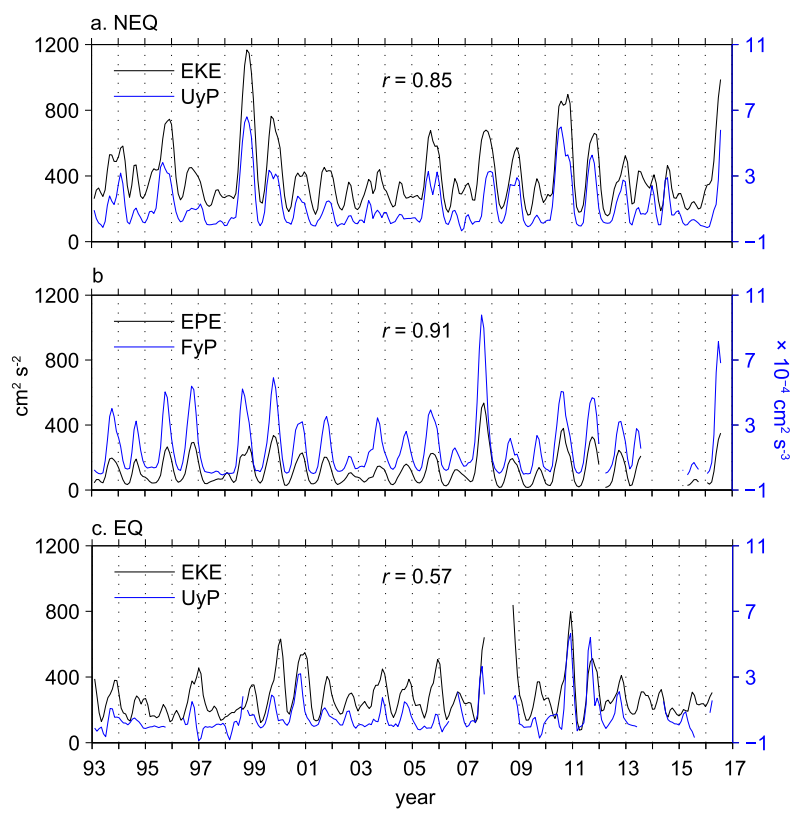

FIG. 7. Interannual variations of EKE or EPE (black curves) and $\mathrm{U}_{\mathrm{y}} \mathrm{P}$ or $\mathrm{F}_{\mathrm{y}} \mathrm{P}$ (blue curves) averaged in (a),(b) NEQ and (c) EQ. The $r$ values are the correlation coefficients between black and blue lines, with all passing the Student's $t$ test at the $99 \%$ confidence level.

\section{c. Seasonal variations of $U_{y}$ and $F_{y}$}

The $\mathrm{U}_{\mathrm{y}} \mathrm{P}$ and $\mathrm{F}_{\mathrm{y}} \mathrm{P}$ are the dominant terms in BTR and BCR, respectively (Figs. 5h,j). To illuminate the mechanisms of how the $\mathrm{U}_{\mathrm{y}} \mathrm{P}$ and $\mathrm{F}_{\mathrm{y}} \mathrm{P}$ transfer energies, they are displayed as

$$
\begin{aligned}
& \mathrm{U}_{\mathrm{y}} \mathrm{P}=-U_{y} M_{u v} \text { and } \\
& \mathrm{F}_{\mathrm{y}} \mathrm{P}=-F_{y} M_{f v},
\end{aligned}
$$

where $M_{u v}=\overline{u^{\prime} v^{\prime}}$ is the eddy momentum flux, representing the meridional transport of momentum induced by eddies; $M_{u v}=g \overline{\varrho^{\prime} v^{\prime}} / N\left(\mathrm{~m}^{2} \mathrm{~s}^{-2}\right)$ is defined as the eddy buoyancy flux and represents the meridional transport of buoyancy induced by eddies.

The NEQ barotropic instability induced by $U_{y}$ acts to reduce $U_{y}$ via opposite eddy momentum fluxes $M_{u v}$ (Fig. 8a), transferring energy from MKE to EKE. The negative relationship between shears and momentum fluxes is called eddy viscosity: $M_{u v}=-v U_{y}$ (McWilliams 2006 , p. 102), where $v$ is the eddy viscosity coefficient with values of $10^{2}-10^{4} \mathrm{~m}^{2} \mathrm{~s}^{-1}$, which should be proportional to the turbulent speed and pathlength (Talley 2011, p. 191). In this case, the $M_{u v}$ grows faster with increasing $U_{y}$ (Fig. 8a). The relationship in the EQ region (Fig. 8e) is not as good as that in Fig. 8a, probably because of the nonlinear effect of Kelvin waves on TIWs and/or the bias in $U_{y}$ from the temperaturederived geostrophic velocity. The NEQ baroclinic 

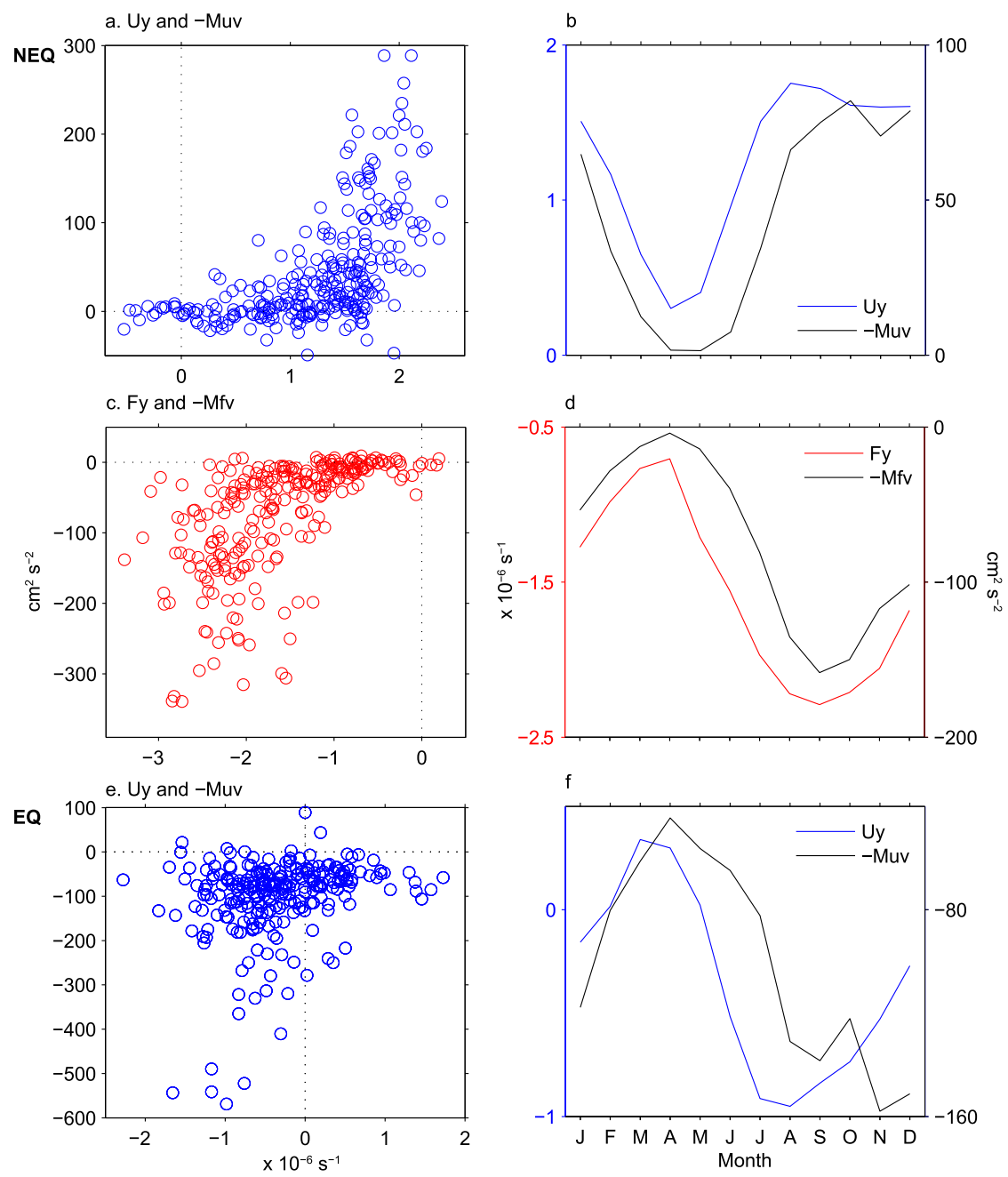

FIG. 8. (left) Scatterplots and (right) seasonal series of NEQ averaged (a),(b) $U_{y}$ (blue curve) and $-M_{u v}$ (black curve); (c),(d) $F_{y}$ (red curve) and $-M_{f v}$ (black curve); and EQ averaged (e),(f) $U_{y}$ (blue curve) and $-M_{u v}$ (black curve). The $x$ axis in the scatter diagrams denotes the $U_{y}$ or $F_{y}$. The variables are defined in Eqs. (5a) and (5b).

instability triggered by the perturbations acts to reduce $F_{y}$ via the opposite eddy buoyancy fluxes $M_{f v}$ (Fig. 8c). The relationship between buoyancy fronts and buoyancy fluxes is the equivalent of eddy viscosity, called eddy diffusivity: $M_{f v}=-\kappa F_{y}$, where $\kappa$ is the eddy diffusivity coefficient with value of $10^{3}-10^{4} \mathrm{~m}^{2} \mathrm{~s}^{-1}$ (Talley 2011, p. 193). This process transfers APE to EPE, which can be converted to EKE via vertical buoyancy works (Holmes and Thomas 2016; Wang et al. 2017).

On a first-order approximation, $v$ and $\kappa$ can be simplified as constants (Figs. $8 \mathrm{~b}, \mathrm{~d}, \mathrm{f}$ ); hence $\mathrm{U}_{\mathrm{y}} \mathrm{P}$ and $\mathrm{F}_{\mathrm{y}} \mathrm{P}$ follow the quadratic relationships of $\mathrm{U}_{\mathrm{y}} \mathrm{P}=v U_{y}^{2}$ and $\mathrm{F}_{\mathrm{y}} \mathrm{P}=\kappa F_{y}^{2}$. It suggests that the seasonality of EKE and EPE are mainly attributed to the seasonal-varying intensities of $U_{y}$ and $F_{y}$, and in phase with $\overline{U_{y}} U_{y}^{\prime}$ and $\overline{F_{y}} F_{y}^{\prime}$ (Figs. 9a,b), respectively, where the bars and primes denote the time means and anomalies and the positive nonlinear terms $U_{y}^{\prime 2}$ and $F_{y}^{\prime 2}$ are omitted. The $\overline{U_{y}} U_{y}^{\prime}$ and $\overline{F_{y}} F_{y}^{\prime}$ both exhibit large seasonality at two latitude bands with one near the equator and another near $5^{\circ} \mathrm{N}$ in association with the seasonal variation of SEC (Fig. 9b). Since the seasonal variation of the NEQ surface buoyancy frequency $N\left(\sim \pm 1.7 \times 10^{-4} \mathrm{~s}^{-1}\right)$ is relatively small in comparison with the mean $N(\sim 1.6 \times$ $10^{-3} \mathrm{~s}^{-1}$ ), the NEQ $F_{y}^{\prime}$ is mainly attributed to the surface density fronts, or the SST fronts $T_{y}$, because sea surface salinity plays a secondary role in the density change.

\section{Air-sea processes governing the EKE seasonality}

The EKE in the eastern equatorial Pacific is enhanced in the second half of year, mainly attributed to the strong 

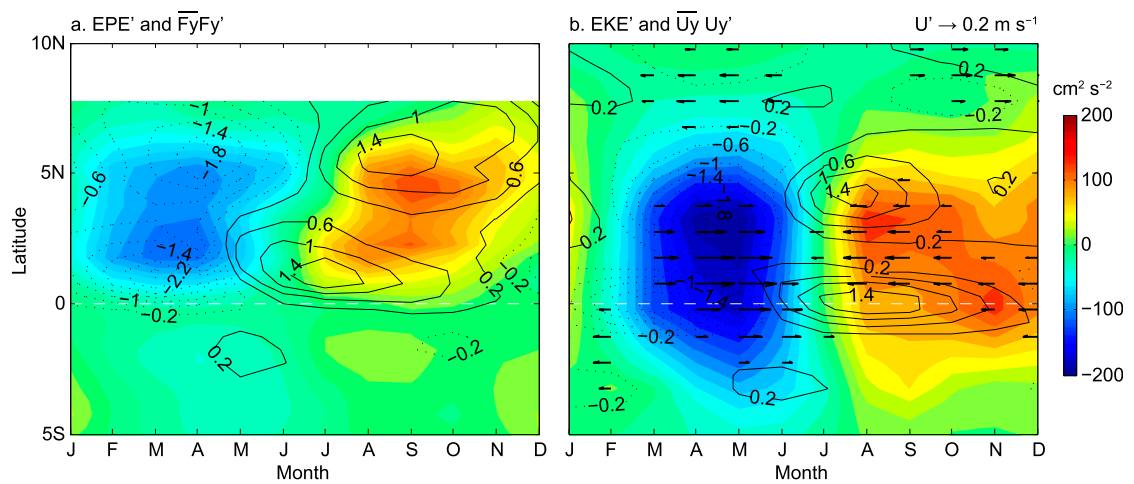

FIG. 9. Season-latitude plots of (a) EPE anomaly (shading) and $\overline{F_{y}} F_{y}^{\prime}$ (contours; $\times 10^{-12} \mathrm{~s}^{-2}$ ) and (b) EKE anomaly (shading), $\overline{U_{y}} U_{y}^{\prime}$ (contours; $\times 10^{-12} \mathrm{~s}^{-2}$ ), and zonal current anomaly (arrow) from AVISO. The EKE is linearly interpolated within $3^{\circ}$ latitude to the equator between the $3^{\circ}$ latitude EKE based on AVISO and the equatorial 35 -m-depth EKE from ADCPs. All are averaged between $155^{\circ}$ and $110^{\circ} \mathrm{W}$, at the surface.

current shears $U_{y}$ and SST fronts $T_{y}$ (Fig. 9). On the other hand, the cross-equatorial southerly winds also intensify in the eastern equatorial Pacific in the second half of year. In this section, we will demonstrate that the seasonal variations of current shears and SST fronts, hence the EKE seasonality, are associated with the intensified southerly winds.

The difference of surface winds between the second and the first half of the year shows southeasterly anomalies in $10^{\circ} \mathrm{S}-3^{\circ} \mathrm{N}$ and southwesterly anomalies in
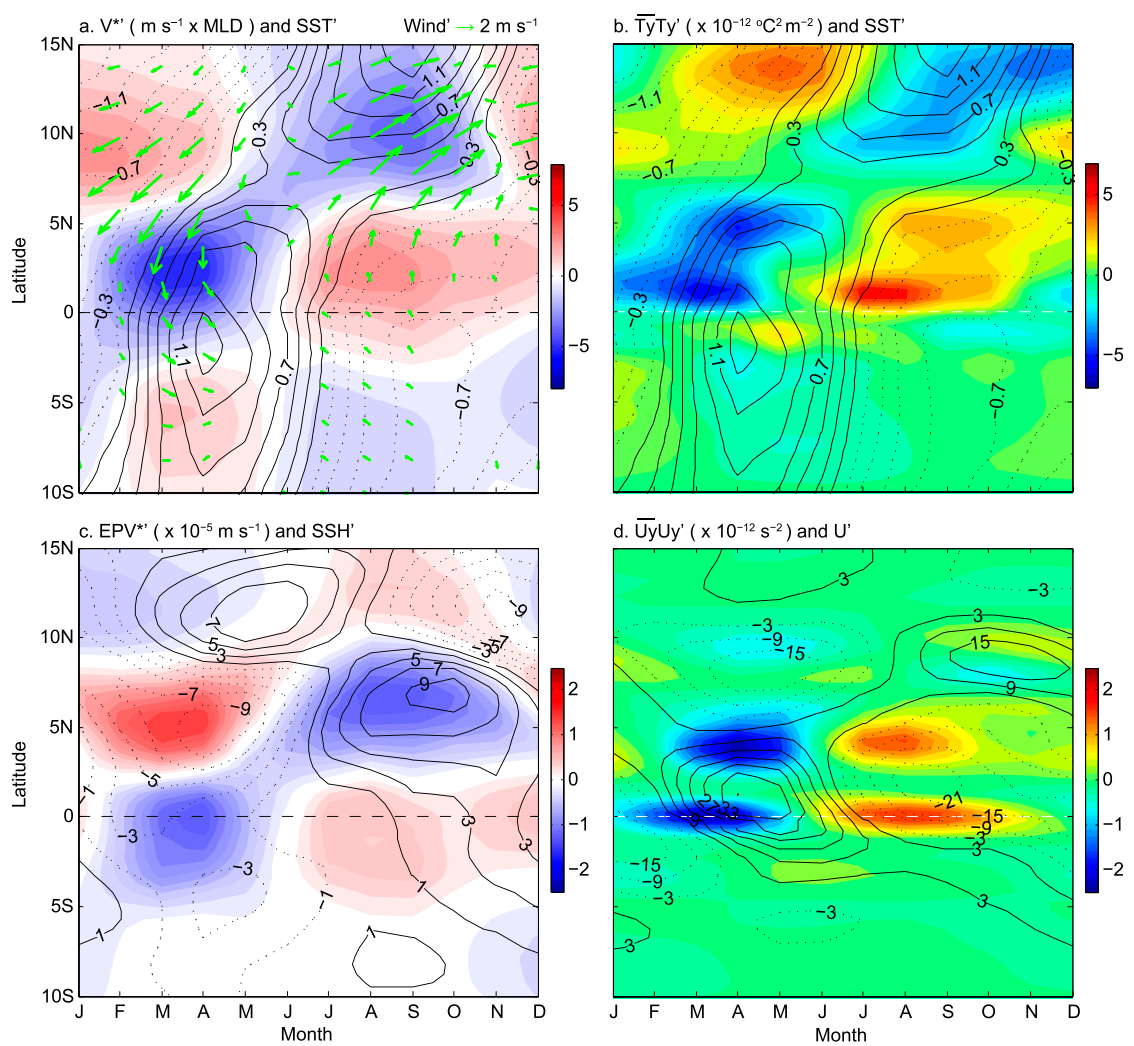

FIG. 10. Season-latitude plots of (a) meridional Ekman transport anomaly (shading) based on Ifremer wind velocity (anomaly; green vectors) with SST anomaly (contours; ${ }^{\circ} \mathrm{C}$ ) overlaid; (b) $\overline{F_{y}} F_{y}^{\prime}$ (shading) and SST anomaly (contours); (c) Ekman pumping velocity anomaly (shading) and SSH anomaly (contours; cm); and (d) $\overline{U_{y}} U_{y}^{\prime}$ (shading) and surface zonal current anomaly (contours; $\mathrm{cm} \mathrm{s}^{-1}$ ) from AVISO. All are averaged between $155^{\circ}$ and $110^{\circ} \mathrm{W}$. 
$3^{\circ}-15^{\circ} \mathrm{N}$ (Fig. 11, left panel). The southeasterly (southwesterly) winds induce the cold (warm) Ekman advection south (north) of the northern equatorial SST fronts to maintain the fronts (Fig. 10a; de Szoeke et al. 2007). The Ekman transports near the equator can be estimated by wind stresses in combination of the classical $f$ term and frictional term (Phlips 1987; Hsieh and Boer 1992; also see appendix C). The southwesterly winds force the equatorward transport north of $\sim 5^{\circ} \mathrm{N}$ mainly via the $f$ effect. The southeasterly winds force the cross-equatorial northward transport from $2^{\circ} \mathrm{S}$ to $5^{\circ} \mathrm{N}$ via both effects (Fig. 10a; Philander and Pacanowski 1980). The equatorial or south equatorial upwelling of cold water can be advected northward and encounter the equatorward advection of warm water, intensifying the SST fronts north of the equator (Fig. 10b). The wind anomalies intensify the northern equatorial SSH ridge and the associated current shears by driving the downwelling Ekman pumping near $5^{\circ} \mathrm{N}$ (Fig. 10c). The SSH anomalies propagate westward as annual Rossby waves, intensifying the current shears on the northern and southern flanks of SEC in the second half of year (Fig. 10d; Wang et al. 2017).

The convergent Ekman transports near $5^{\circ} \mathrm{N}$ are dominated by the $f$ effect of the anticyclonic wind curl anomalies (Fig. 11, right panel) in association with the rightward turning of the southerly winds (Fig. 11, left panel). A simplified vorticity equation is derived to explore the mechanisms responsible for the turning. Since the zonal pressure gradient force is relatively weak and can be neglected, the zonal momentum equation in the atmospheric mixed layer is simplified to be the balance between Coriolis force and a linearized frictional force (Lindzen and Nigam 1987):

$$
\beta y W_{v}^{\prime}=A W_{u}^{\prime} .
$$

Via a meridional derivative of Eq. (6), we obtain the simplified vorticity equation

$$
\underbrace{-\partial W_{u}^{\prime} / \partial y}_{\xi}=\underbrace{-\frac{1}{l} W_{v}^{\prime}}_{\beta \text { term }}+\underbrace{-\frac{y}{l} \partial W_{v}^{\prime} / \partial y}_{\text {stretching term }},
$$

where $W_{u}$ and $W_{v}$ are the surface zonal and meridional wind velocities and the primes denote the monthly anomalies after removing the annual mean. The surface vorticity $\xi=-\partial W_{u}^{\prime} / \partial y$, where $\partial W_{v}^{\prime} / \partial x$ has been neglected. The damping rate $A=1.5 \times 10^{-5} \mathrm{~s}^{-1}=0.77 \mathrm{day}^{-1}$ (Back and Bretherton 2009), the corresponding length scale of the turning $l=A / \beta=650 \mathrm{~km}$.

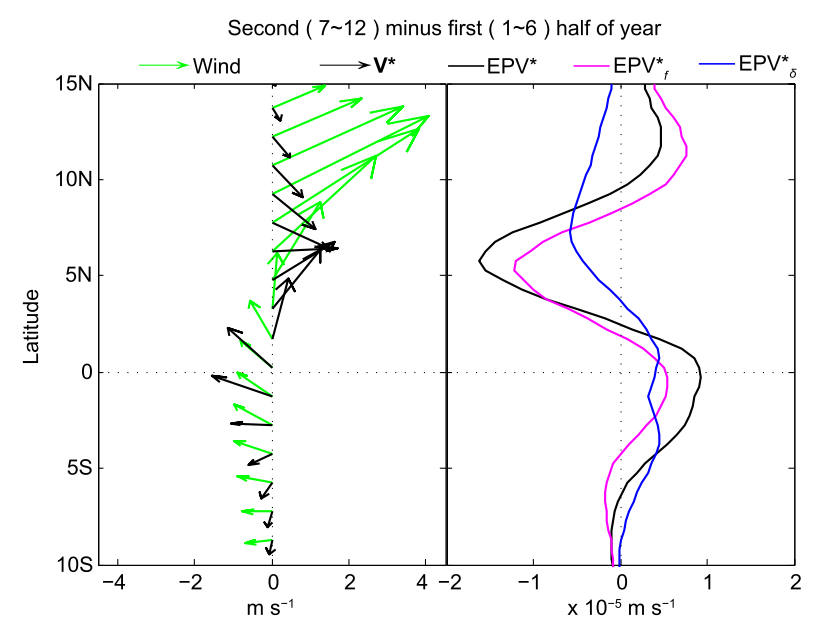

FIG. 11. Meridional sections of wind vector (green arrows; the meridional components are divided by a factor of 1.5 for plotting), Ekman transport vector (black arrows; $\mathrm{m} \mathrm{s}^{-1} \times$ mixed layer depth, divided by 5 for plotting), the total Ekman pumping velocity (black curve), the $f$ effect-driving EPV (magenta curve), and the frictiondriving EPV (blue curve) defined in Eq. (C3). All are displayed as second (July-December) minus first (January-June) half of year, averaged between $155^{\circ}$ and $110^{\circ} \mathrm{W}$.

In Eq. (7), the vorticity anomalies are equal to the sum of $\beta$ and stretching terms in response to the meridional motions and convergence, respectively, which has been demonstrated by the Ifremer wind in terms of annual cycle (Figs. 12a,b). The $\beta$ and stretching effects are both important to regulate the vorticity near $5^{\circ} \mathrm{N}$ (Figs. 12c,d). The anticyclonic wind curl anomalies in the second half of year are related to the southerly winds and also the surface wind divergence between the equator and the northward-displaced ITCZ. Thus, through the $\beta$ effect and the surface wind divergence, the southerly winds generate the anticyclonic southwesterly wind anomalies between $3^{\circ}$ and $8^{\circ} \mathrm{N}$, which force the convergent Ekman transports to intensify the shears and fronts in the second half of year. The above analysis shows that the southerly winds are key to the EKE seasonality.

\section{Summary and discussion}

Using satellite and in situ observations, the present study shows that the cross-equatorial southerly winds are the primary atmospheric forcing that drives the seasonal EKE variability in the eastern equatorial Pacific Ocean. The prevailing southerly winds in the second half of the year provide favorable conditions for the EKE production. Through the $\beta$ effect and the surface wind divergence, the southerly winds generate anticyclonic wind curls north of the equator, which force the meridional, convergent Ekman transports centered near $5^{\circ} \mathrm{N}$ (Fig. 11). On one hand, the Ekman transports 

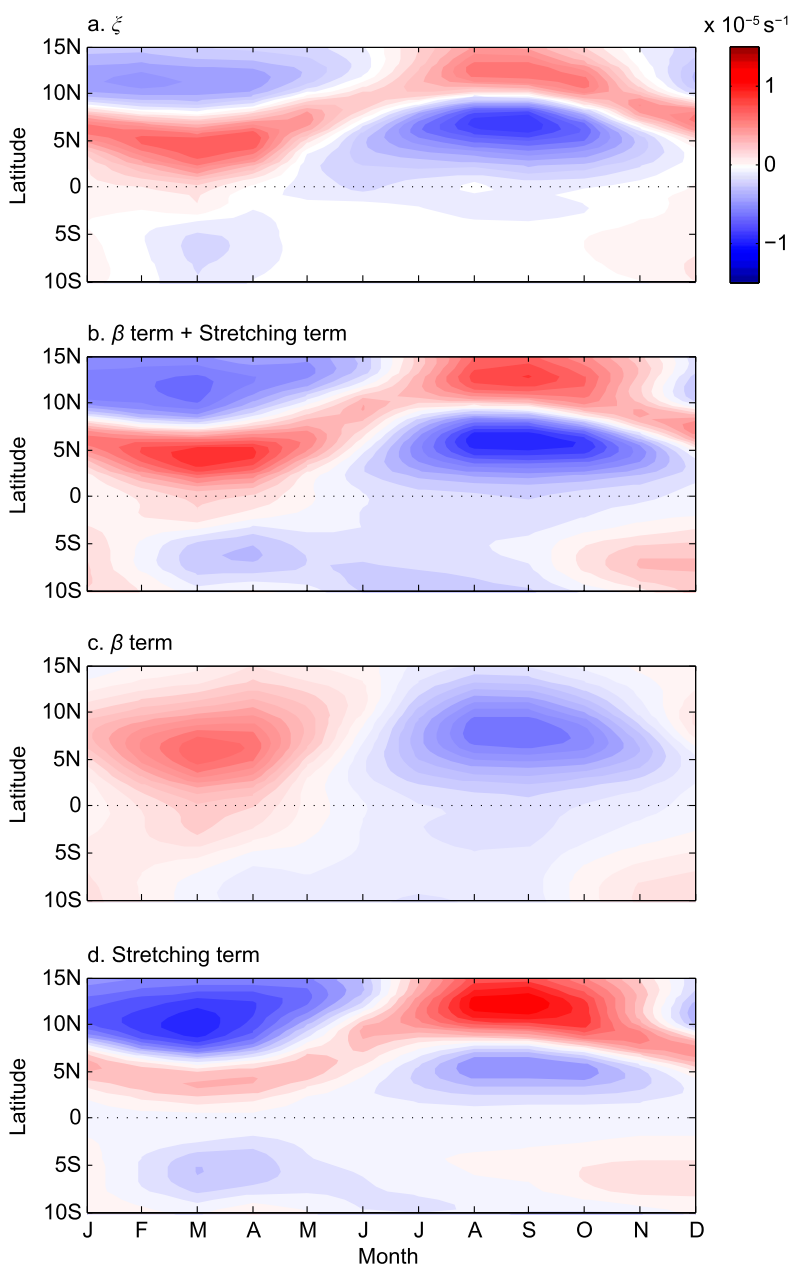

FIG. 12. Season-latitude plots of (a) $\xi$ anomaly [the left-hand side of Eq. (7)], (b) the sum of the $\beta$ and stretching terms [the righthand side of Eq. (7)], (c) the $\beta$ term, and (d) the stretching term. All are averaged between $155^{\circ}$ and $110^{\circ} \mathrm{W}$, based on the Ifremer wind.

intensify the northern equatorial SST fronts by the opposite cold and warm advections (Figs. 10a,b). On the other hand, the downwelling Ekman pumping forces annual Rossby waves propagating westward. The resultant SSH ridge at $5^{\circ} \mathrm{N}$ gives rise to the strong current shears between $0^{\circ}$ and $5^{\circ} \mathrm{N}$ in association with the strengthened SEC (Figs. 10c,d). Via the barotropic and baroclinic instabilities, the intensified current shears and SST fronts lead to EKE generations from summer to winter (Fig. 9).

The southeast winds prevail in the eastern equatorial Pacific with the ITCZ staying north of the equator (Philander and Pacanowski 1981; Xie and Philander 1994; Philander et al. 1996; Xie 2004). The southerly winds intensify north of the equator in the second half of the year. The ITCZ migrates northward from $5^{\circ}$ to $10^{\circ} \mathrm{N}$ during boreal summer and fall in response to the seasonal solar radiation, resulting in a meridional dipole of
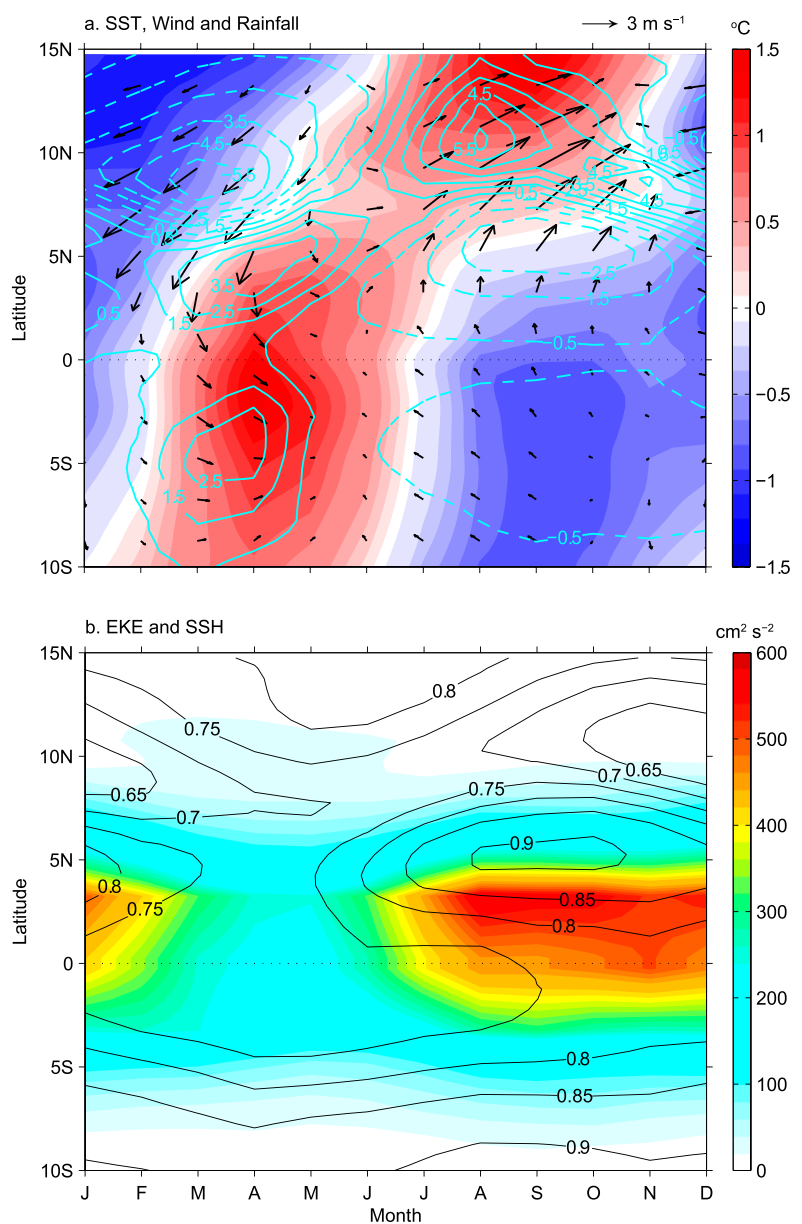

FIG. 13. Season-latitude plots of (a) SST anomaly (shading), wind vector anomaly (arrows), and daily rainfall anomaly (cyan contours; $\mathrm{mm} \mathrm{day}^{-1}$ ) and (b) seasonal mean SSH (black contours; $\mathrm{m}$ ) and surface EKE (shading), linearly interpolated within $3^{\circ}$ to the equator between the off-equatorial EKE based on AVISO and the equatorial 35-m-depth EKE from ADCPs. All are averaged between $155^{\circ}$ and $110^{\circ} \mathrm{W}$.

rainfall anomaly and the southerly wind anomaly north of the equator (Fig. 13a). Alternatively, the strengthened southerly winds and SST fronts in the second half of year may be viewed as coupled (Fig. 13a). Away from the rainfall dipole, wind anomalies are weak south of the equator. The strengthened southerly winds north of the equator generate strong anticyclonic wind curls to intensify the shears and fronts. Therefore, the northwarddisplaced ITCZ and its seasonal migration strengthen the southerly winds and hence the oceanic eddy generations during summer to winter (Fig. 13b).

Mesoscale eddy activities in the eastern equatorial Pacific Ocean can feedback to the surface winds via two different mechanisms. One mechanism is that the SST affects the surface wind speeds by changing the stratification of the atmospheric boundary layer (Wallace 
et al. 1989; Minobe et al. 2008; Ma et al. 2016), with stronger (weaker) surface winds over the warm (cold) water. The other mechanism is that the SST fronts force the surface winds accelerating or decelerating in the near-equatorial region by changing the pressure gradient (Hayes et al. 1989; Chelton et al. 2001; Small et al. 2008). Since the equatorial SST fronts are induced to be cusp-like by TIWs, the southeasterly winds can be perturbed via both mechanisms noted above (Xie et al. 1998; Chelton et al. 2001). Therefore, TIWs in the eastern equatorial Pacific Ocean can significantly affect the speed and direction of the surface winds over the equatorial SST fronts region. In this paper, the feedback of TIWs on the surface winds is not taken into account. Moreover, the ocean turbulent mixing and lateral eddy heat transport are much stronger in the high EKE region (Smyth and Moum 2013; Moum et al. 2013; Tanaka et al. 2015; Liu et al. 2016), which can impact on the equatorial SST and the surface winds. Future studies are thus needed to estimate the impact and coupling effect of the TIWs on the equatorial SST and the southerly winds.

Acknowledgments. We thank two reviewers for their constructive comments on the early versions of this paper. This work is supported by the National Natural Science Foundation of China (41525019, 41830538, 41521005), the Strategic Priority Research Program of the Chinese Academy of Sciences (XDA19060501), the State Oceanic Administration of China (GASI-IPOVAI-02), and, the National Basic Research Program of China (2018YFA0605704). We thank CNES for providing the AVISO data (http://www.aviso.altimetry.fr/en/ data/data-access.html), the GTMBA Project Office of NOAA/PMEL for the TAO observations (https:// www.pmel.noaa.gov/tao/drupal/disdel/), Scripps Institution of Oceanography for the Argo dataset (http:// www.argo.ucsd.edu/), and APDRC for the Ifremer wind data access (http://apdrc.soest.hawaii.edu/datadoc/ ifremer_LOPS_blended_wind_6hourly.php), the OISST data (http://apdrc.soest.hawaii.edu/datadoc/oisst_ avhrr.php), and the TMI rainfall data (http:// apdrc.soest.hawaii.edu/datadoc/trmm_tmi_3day.php). We thank Phil Morgan and C. Torrence for releasing the MATLAB toolboxes of "SEAWATER" (in 1993) and "WAVELET" (in 1998), respectively.

\section{APPENDIX A}

\section{Estimating Density}

Densities are estimated from temperatures by a linear regression model between densities and temperatures due to the shortage of salinity observations in step with the temperatures

$$
\begin{aligned}
\hat{\rho}(x, y, z, t) / \rho_{0}= & -\alpha^{*}(x, y, z) T(x, y, z, t) \\
& +\tilde{\rho}(x, y, z) / \rho_{0},
\end{aligned}
$$

where $\hat{\rho}$ is the density calculated by the regression, $T$ is the temperature from moorings and OISST, $\rho_{0}=1024 \mathrm{~kg} \mathrm{~m}^{-3}$, and $\alpha^{*}\left({ }^{\circ} \mathrm{C}^{-1}\right)$ and $\tilde{\rho}(x, y, z) / \rho_{0}$ are the slope and intercept of the regression estimated by the Argo temperature and salinity. The Argo dataset used is the 2004-16, monthly, $1^{\circ} \times 1^{\circ}$ gridded dataset produced by optimal interpolation from the Scripps Institution of Oceanography. The slope $\alpha^{*}$ varies from $1.5 \times 10^{-4}{ }^{\circ} \mathrm{C}^{-1}$ below the thermocline up to $5.0 \times 10^{-4}{ }^{\circ} \mathrm{C}^{-1}$ at the surface beneath ITCZ. Given that the thermal expansion coefficient of the warm seawater is generally about $3 \times 10^{-4}{ }^{\circ} \mathrm{C}^{-1}$, the large value of $\alpha^{*}$ implies that the salinity contributes significantly to the density variability in the ITCZ region. Nevertheless, the density change of the tropical seawater can be inferred from temperature, and the linear regression model works well, since the time correlation coefficients between the Argo temperatures and densities are $\geq 0.95$ in most of the region of our interest and $\geq$ 0.85 in the ITCZ region (figure not shown). The results $\hat{\rho} / \rho_{0}$, written as $\varrho$ for short in the paper, are linearly subsampled to a 3-day time interval and interpolated to a 5-m depth interval.

\section{APPENDIX B}

\section{Estimating $U_{y}$ on the Equator}

On the first-order geostrophic approximation, after removing the ageostrophic meridional gradients on the equator (Picaut and Tournier 1991), $U_{g}(y)$ is given by

$$
\begin{aligned}
U_{g} & =-\overline{\Phi_{y}^{*}} /(\beta y), \\
\Phi^{*} & =\Phi-y \Phi_{y}^{y=0} e^{-y^{2} / r^{2}}, \quad \text { and } \\
\Phi(x, y, z, t) & =g\left[h(x, y, 0, t)+\frac{1}{\rho_{0}} \int_{z}^{0} \varrho\left(x, y, z^{\prime}, t\right) d z^{\prime}\right],
\end{aligned}
$$

where $\Phi$ is the geopotential height, calculated in Eq. (B3) from SSH and $\varrho$ on the hydrostatic balance. In Eq. (B2), $\Phi^{*}$ is the geostrophically balanced geopotential height after removing the ageostrophic part $y \Phi_{y}^{y=0} e^{-y^{2} / r^{2}}$ within the equatorial radius of deformation $r=[c /(2 \beta)]^{1 / 2}$ (Gill and Clarke 1974) to the equator, where the phase velocity of long gravity wave $c=$ $2.8 \mathrm{~m} \mathrm{~s}^{-1}$ and $r=247 \mathrm{~km}$. The $\overline{\Phi^{*}}$ in Eq. (B1) denotes the 33-day running mean of $\Phi^{*}$. 

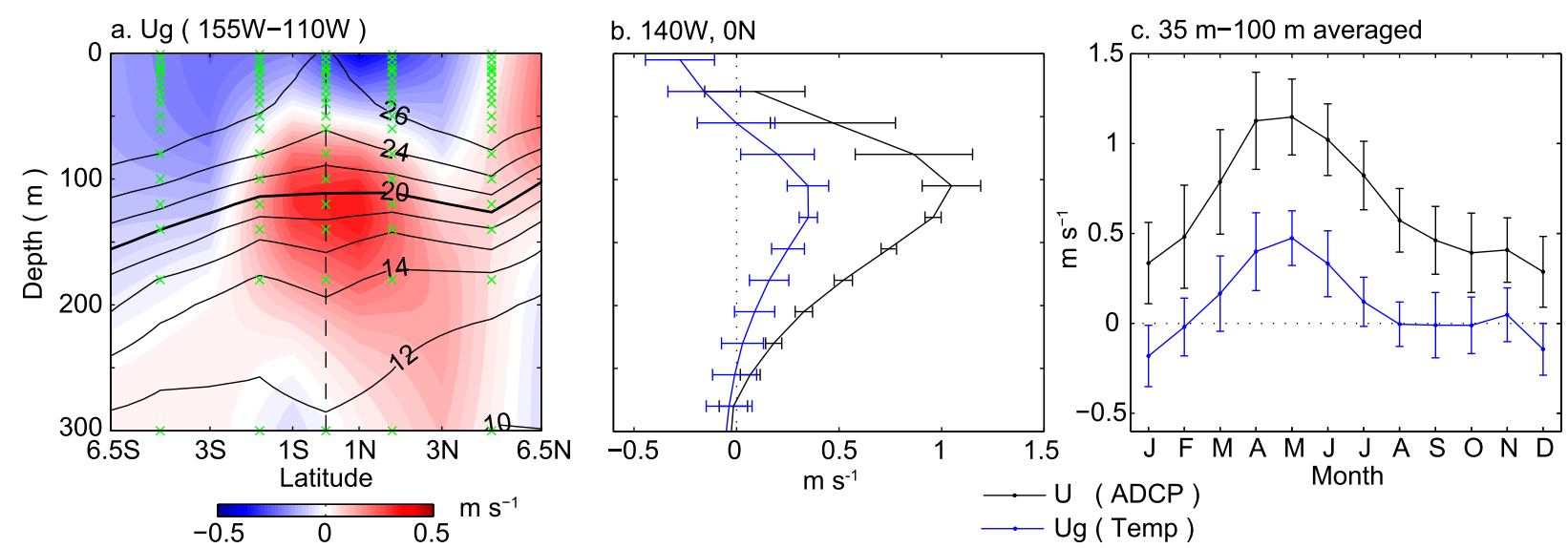

FIG. B1. (a) Mean zonal geostrophic velocity (shading) based on temperature moorings (green times signs) with isotherms (contours; ${ }^{\circ} \mathrm{C}$ ) overlaid, averaged between $155^{\circ}$ and $110^{\circ} \mathrm{W}$. Also shown are comparisons between the $U_{g}$ (blue curve) and the ADCP measurements (black curve) at $0^{\circ}, 140^{\circ} \mathrm{W}$ in the (b) vertical and (c) seasonal variations. Error bars in (b) and (c) denote their seasonal and interannual variabilities, respectively. Notice that the $U_{g}$ in (b) and (c) are calculated by the three temperature moorings at $140^{\circ} \mathrm{W}$ and $2^{\circ} \mathrm{S}, 0^{\circ}$, and $2^{\circ} \mathrm{N}$.

From the temperature moorings, Fig. B1a shows the estimated $U_{g}\left(y=6.5^{\circ} \mathrm{S}, 3^{\circ} \mathrm{S}, 1^{\circ} \mathrm{S}, 1^{\circ} \mathrm{N}, 3^{\circ} \mathrm{N}\right.$, and $\left.6.5^{\circ} \mathrm{N}\right)$ with the eastward EUC centered on the equator and the westward surface SEC (its northern branch between $1^{\circ} \mathrm{S}$ and $5^{\circ} \mathrm{N}$ ). Strong horizontal current shears exist between SEC and NECC and in the southern flank of SEC. When compared with the ADCP observations at $0^{\circ}, 140^{\circ} \mathrm{W}$, it is seen that

$$
U_{g}\left(0^{\circ} \mathrm{N}\right)=\left[U_{g}\left(1^{\circ} \mathrm{S}\right)+U_{g}\left(1^{\circ} \mathrm{N}\right)\right] / 2
$$

captures the vertical and seasonal variability of the equatorial zonal currents in the upper ocean (Figs. B1b,c), although the estimated EUC is too weak because of the $2^{\circ}$ latitude interval between moorings and/or the omitted ageostrophic motions (Philander and Pacanowski 1980). We use

$$
\left[U_{g}\left(1^{\circ} \mathrm{N}\right)-U_{g}\left(1^{\circ} \mathrm{S}\right)\right] / 2^{\circ}
$$

to represent the current shears on the equator.

\section{APPENDIX C}

\section{Estimating Equatorial Ekman Transports and EPV}

The near-equatorial Ekman transports are derived from the following momentum balance between Coriolis force, wind stress, and frictional damping term in the mixed layer (Phlips 1987; Hsieh and Boer 1992):

$$
\left\{\begin{array} { l } 
{ \delta U ^ { * } - f V ^ { * } = \tau ^ { x } / \rho _ { 0 } } \\
{ \delta V ^ { * } + f U ^ { * } = \tau ^ { y } / \rho _ { 0 } }
\end{array} \rightarrow \left\{\begin{array}{l}
U^{*}=\underbrace{\frac{f \tau^{y}}{\rho_{0}\left(f^{2}+\delta^{2}\right)}}_{U_{f}^{*}}+\underbrace{\frac{\delta \tau^{x}}{\rho_{0}\left(f^{2}+\delta^{2}\right)}}_{U_{\delta}^{*}} \\
V^{*}=\underbrace{\frac{-f \tau^{x}}{\rho_{0}\left(f^{2}+\delta^{2}\right)}}_{V_{f}^{*}}+\underbrace{\frac{\delta \tau^{y}}{\rho_{0}\left(f^{2}+\delta^{2}\right)}}_{V_{\delta}^{*}}
\end{array} \quad\right.\right. \text { and }
$$

$$
\mathrm{EPV}^{*}=\nabla \cdot \mathbf{V}^{*}=\underbrace{\nabla \cdot \mathbf{V}_{f}^{*}}_{\mathrm{EPV}_{f}^{*}}+\underbrace{\nabla \cdot \mathbf{V}_{\delta}^{*}}_{\mathrm{EPV}_{\delta}^{*}},
$$

where $\mathbf{V}^{*}=\left(U^{*}, V^{*}\right)$ are the horizontal volume transports in the mixed layer, $\mathrm{EPV}^{*}$ is the Ekman pumping velocity at the bottom of the mixed layer, $\tau^{x}$ and $\tau^{y}$ are the zonal and meridional wind stresses, $f$ is the Coriolis parameter, and $\delta$ is a frictional damping parameter. The $\mathbf{V}_{f}^{*}=\left(U_{f}^{*}, V_{f}^{*}\right)$ denote the crosswind transports via the $f$ effect, and $\mathbf{V}_{f}^{*}=\left(U_{f}^{*}, V_{f}^{*}\right)$ are the along-wind transports via the frictional effect. In this study, $f=\beta y$ and $\delta=\beta r$, 
where $r=247 \mathrm{~km}$ is the equatorial radius of deformation, giving $\delta=5.7 \times 10^{-6} \mathrm{~s}^{-1}$, which is approximately 2 times the $\delta=2.4 \times 10^{-6} \mathrm{~s}^{-1}$ used in Hsieh and Boer (1992). Therefore, the estimated total transports should be smaller and the ratio of the friction terms larger than those in Hsieh and Boer (1992). Here, $\left(\tau^{x}, \tau^{y}\right)=\rho_{a} C_{D} W\left(W_{u}, W_{v}\right)$, where $\left(W_{u}, W_{v}\right)$ are the zonal and meridional wind velocities, the air density constant $\rho_{a}=1.3 \mathrm{~kg} \mathrm{~m}^{-3}$, the drag coefficient $C_{D}=1.4 \times 10^{-3}$ (Xie and Philander 1994), and $W$ is the surface wind speed.

\section{REFERENCES}

Back, L. E., and C. S. Bretherton, 2009: On the relationship between SST gradients, boundary layer winds, and convergence over the tropical oceans. J. Climate, 22, 4182-4196, https:// doi.org/10.1175/2009JCLI2392.1.

Baturin, N., and P. Niiler, 1997: Effects of instability waves in the mixed layer of the equatorial Pacific. J. Geophys. Res., 102, 27 771-27 793, https://doi.org/10.1029/97JC02455.

Brown, J. N., J. S. Godfrey, and S. E. Wijffels, 2010: Nonlinear effects of tropical instability waves on the equatorial Pacific circulation. J. Phys. Oceanogr., 40, 381-393, https://doi.org/ 10.1175/2009JPO3963.1.

Chelton, D. B., and Coauthors, 2001: Observations of coupling between surface wind stress and sea surface temperature in the eastern tropical Pacific. J. Climate, 14, 1479-1498, https://doi.org/ 10.1175/1520-0442(2001)014<1479:OOCBSW > 2.0.CO;2.

_, S. K. Esbensen, and R. M. Samelson, 2011: Global observations of nonlinear mesoscale eddies. Prog. Oceanogr., 91, 167-216, https://doi.org/10.1016/j.pocean.2011.01.002.

Cox, M. D., 1980: Generation and propagation of 30-day waves in a numerical-model of the Pacific. J. Phys. Oceanogr., 10, 1168-1186, https://doi.org/10.1175/1520-0485(1980)010<1168: GAPODW $>2.0 . \mathrm{CO} ; 2$.

de Szoeke, S. P., S. P. Xie, T. Miyama, K. J. Richards, and R. J. O. Small, 2007: What maintains the SST front north of the eastern Pacific equatorial cold tongue? J. Climate, 20, 2500-2514, https://doi.org/10.1175/JCLI4173.1.

Duing, W., and Coauthors, 1975: Meanders and long waves in equatorial Atlantic. Nature, 257, 280-284, https://doi.org/ 10.1038/257280a0.

Eriksen, C. C., M. B. Blumenthal, S. P. Hayes, and P. Ripa, 1983: Wind-generated equatorial Kelvin waves observed across the Pacific Ocean. J. Phys. Oceanogr., 13, 1622-1640, https://doi.org/ 10.1175/1520-0485(1983)013<1622:WGEKWO>2.0.CO;2.

Farrar, J. T., 2011: Barotropic Rossby waves radiating from tropical instability waves in the Pacific Ocean. J. Phys. Oceanogr., 41, 1160-1181, https://doi.org/10.1175/2011JPO4547.1.

Flament, P. J., S. C. Kennan, R. A. Knox, P. P. Niiler, and R. L. Bernstein, 1996: The three-dimensional structure of an upper ocean vortex in the tropical Pacific Ocean. Nature, 383, 610-613, https://doi.org/10.1038/383610a0.

Gill, A. E., and A. J. Clarke, 1974: Wind-induced upwelling, coastal currents and sea-level changes. Deep-Sea Res. Oceanogr. Abstr., 21, 325-345, https://doi.org/10.1016/0011-7471(74)90038-2.

Hansen, D. V., and C. A. Paul, 1984: Genesis and effects of long waves in the equatorial Pacific. J. Geophys. Res., 89, 10 431-10 440, https://doi.org/10.1029/JC089iC06p10431.

Harrison, D. E., and B. S. Giese, 1988: Remote westerly wind forcing of the eastern equatorial Pacific; Some model results.
Geophys. Res. Lett., 15, 804-807, https://doi.org/10.1029/ GL015i008p00804.

Hayes, S. P., M. J. McPhaden, and J. M. Wallace, 1989: The influence of sea-surface temperature on surface wind in the eastern equatorial Pacific: Weekly to monthly variability. J. Climate, $\mathbf{2}$, 1500-1506, https://doi.org/10.1175/1520-0442(1989)002<1500: TIOSST $>2.0 . \mathrm{CO} ; 2$.

Holmes, R. M., and L. N. Thomas, 2016: Modulation of tropical instability wave intensity by equatorial Kelvin waves. J. Phys. Oceanogr., 46, 2623-2643, https://doi.org/10.1175/JPO-D-16-0064.1.

Hsieh, W. W., and G. J. Boer, 1992: Global climate change and ocean upwelling. Fish. Oceanogr., 1, 333-338, https://doi.org/ 10.1111/j.1365-2419.1992.tb00005.x.

Jochum, M., M. F. Cronin, W. S. Kessler, and D. Shea, 2007: Observed horizontal temperature advection by tropical instability waves. Geophys. Res. Lett., 34, L09604, https:// doi.org/10.1029/2007GL029416.

Johnson, E. S., and M. J. McPhaden, 1993: Structure of intraseasonal Kelvin waves in the equatorial Pacific Ocean. J. Phys. Oceanogr., 23, 608-625, https://doi.org/10.1175/1520-0485(1993) $023<0608$ :SOIKWI $>2.0$. CO 2 .

Kennan, S. C., and P. J. Flament, 2000: Observations of a tropical instability vortex. J. Phys. Oceanogr., 30, 2277-2301, https:// doi.org/10.1175/1520-0485(2000)030<2277:OOATIV $>$ 2.0.CO;2.

Kessler, W. S., M. J. McPhaden, and K. M. Weickmann, 1995: Forcing of intraseasonal Kelvin waves in the equatorial Pacific. J. Geophys. Res., 100, 10 613-10 631, https://doi.org/10.1029/95JC00382.

Legeckis, R., 1977: Long waves in the eastern equatorial Pacific Ocean: A view from a geostationary satellite. Science, 197, 1179-1181, https://doi.org/10.1126/science.197.4309.1179.

_ W. Wichel, and G. Nesterczuk, 1983: Equatorial long waves in geostationary satellite observations and in a multichannel sea surface temperature analysis. Bull. Amer. Meteor. Soc., 64, 133-139, https://doi.org/10.1175/1520-0477(1983)064<0133: ELWIGS $>2.0 . \mathrm{CO} ; 2$.

Lindzen, R. S., and S. Nigam, 1987: On the role of sea surface temperature gradients in forcing low-level winds and convergence in the tropics. J. Atmos. Sci., 44, 2418-2436, https://doi.org/ 10.1175/1520-0469(1987)044<2418:OTROSS > 2.0.CO;2.

Liu, C. Y., A. Kohl, Z. Y. Liu, F. Wang, and D. Stammer, 2016: Deepreaching thermocline mixing in the equatorial Pacific cold tongue. Nat. Commun., 7, 11576, https://doi.org/10.1038/ncomms11576.

Luther, D. S., and E. S. Johnson, 1990: Eddy energetics in the upper equatorial Pacific during the Hawaii-to-Tahiti Shuttle Experiment. J. Phys. Oceanogr., 20, 913-944, https://doi.org/10.1175/ 1520-0485(1990)020<0913:EEITUE > 2.0.CO;2.

Lyman, J. M., D. B. Chelton, R. A. deSzoeke, and R. M. Samelson, 2005: Tropical instability waves as a resonance between equatorial Rossby waves. J. Phys. Oceanogr., 35, 232-254, https://doi.org/10.1175/JPO-2668.1.

, G. C. Johnson, and W. S. Kessler, 2007: Distinct 17-and 33-day tropical instability waves in subsurface observations. J. Phys. Oceanogr., 37, 855-872, https://doi.org/10.1175/JPO3023.1.

Ma, X., and Coauthors, 2016: Western boundary currents regulated by interaction between ocean eddies and the atmosphere. Nature, 535, 533, https://doi.org/10.1038/nature18640.

Mallat, S., 1999: A Wavelet Tour of Signal Processing. Elsevier, $620 \mathrm{pp}$.

Masina, S., S. G. H. Philander, and A. B. G. Bush, 1999: An analysis of tropical instability waves in a numerical model of the Pacific Ocean: 2. Generation and energetics of the waves. J. Geophys. Res., 104, 29 637-29 661, https://doi.org/10.1029/1999JC900226. 
Matsuno, T., 1966: Quasi-geostrophic motions in the equatorial area. J. Meteor. Soc. Japan Ser. II, 44, 25-43, https://doi.org/ 10.2151/jmsj1965.44.1_25.

McPhaden, M. J., and Coauthors, 1998: The Tropical Ocean-Global Atmosphere observing system: A decade of progress. J. Geophys. Res., 103, 14169-14240, https://doi.org/10.1029/97JC02906.

McWilliams, J. C., 2006: Barotropic and vortex dynamics. Fundamentals of Geophysical Fluid Dynamics, Cambridge University Press, 102-103.

Miller, L., D. R. Watts, and M. Wimbush, 1985: Oscillations of dynamic topography in the eastern equatorial Pacific. J. Phys. Oceanogr., 15, 1759-1770, https://doi.org/10.1175/15200485(1985)015<1759:OODTIT>2.0.CO;2.

Minobe, S., A. Kuwano-Yoshida, N. Komori, S. P. Xie, and R. J. Small, 2008: Influence of the Gulf Stream on the troposphere. Nature, 452, 206, https://doi.org/10.1038/nature06690.

Moum, J. N., A. Perlin, J. D. Nash, and M. J. McPhaden, 2013: Seasonal sea surface cooling in the equatorial Pacific cold tongue controlled by ocean mixing. Nature, 500, 64-67, https:// doi.org/10.1038/nature12363.

Pezzi, L. P., J. Vialard, K. J. Richards, C. Menkes, and D. Anderson, 2004: Influence of ocean-atmosphere coupling on the properties of tropical instability waves. J. Geophys. Res., 31, L16306, https://doi.org/10.1029/2004GL019995.

Philander, S. G. H., 1978: Instabilities of zonal equatorial currents, 2. J. Geophys. Res., 83, 3679-3682, https://doi.org/10.1029/ JC083iC07p03679.

—, and R. C. Pacanowski, 1980: The generation of equatorial currents. J. Geophys. Res., 85, 1123-1136, https://doi.org/ 10.1029/JC085iC02p01123.

— winds (with application to coastal upwelling in low latitudes). Tellus, 33, 201-210, https://doi.org/10.3402/tellusa.v33i2.10708.

—, D. Gu, G. Lambert, T. Li, D. Halpern, N. Lau, and R.C. Pacanowski, 1996: Why the ITCZ is mostly north of the equator. J. Climate, 9, 2958-2972, https://doi.org/10.1175/15200442(1996)009<2958:WTIIMN $>2.0$. CO;2.

Phlips, P. J., 1987: A simple model of the wind-driven tropical ocean. J. Phys. Oceanogr., 17, 2003-2015, https://doi.org/ 10.1175/1520-0485(1987)017<2003:ASMOTW>2.0.CO;2.

Picaut, J., and R. Tournier, 1991: Monitoring the 1979-1985 equatorial Pacific current transports with expendable bathythermograph data. J. Geophys. Res., 96, 3263-3277, https:// doi.org/10.1029/90JC02066.

Qiao, L., and R. H. Weisberg, 1995: Tropical instability wave kinematics: Observations from the Tropical Instability Wave Experiment (TIWE).J. Geophys. Res., 100, 8677-8693, https:// doi.org/10.1029/95JC00305.

—, and _ 1998: Tropical instability wave energetics: Observations from the Tropical Instability Wave Experiment. J. Phys. Oceanogr., 28, 345-360, https://doi.org/10.1175/15200485(1998)028<0345:TIWEOF $>2.0$. CO;2.

Semtner, A. J., Jr., and W. R. Holland, 1980: Numerical simulation of equatorial ocean circulation. Part I: A basic case in turbulent equilibrium. J. Phys. Oceanogr., 10, 667-693, https://doi.org/ 10.1175/1520-0485(1980)010<0667:NSOEOC $>2.0 . C O ; 2$.

Small, R. J., and Coauthors, 2008: Air-sea interaction over ocean fronts and eddies. Dyn. Atmos. Oceans, 45, 274-319, https:// doi.org/10.1016/j.dynatmoce.2008.01.001.

— K. K. Richards, S. P. Xie, P. Dutrieux, and T. Miyama, 2009: Damping of tropical instability waves caused by the action of surface currents on stress. J. Geophys. Res., 114, C04009, https://doi.org/10.1029/2008JC005147.
Smyth, W. D., and J. N. Moum, 2013: Marginal instability and deep cycle turbulence in the eastern equatorial Pacific Ocean. Geophys. Res. Lett., 40, 6181-6185, https://doi.org/10.1002/2013GL058403.

Talley, L. D., 2011: Eddy viscosity and eddy diffusivity. Descriptive Physical Oceanography: An Introduction. Academic Press, 191-193.

Tanaka, Y., T. Hibiya, and H. Sasaki, 2015: Downward lee wave radiation from tropical instability waves in the central equatorial Pacific Ocean: A possible energy pathway to turbulent mixing. J. Geophys. Res., 120, 7137-7149, https://doi.org/ 10.1002/2015JC011017.

Wallace, J. M., T. P. Mitchell, and C. Deser, 1989: The influence of sea-surface temperature on surface wind in the eastern equatorial Pacific: Seasonal and interannual variability. J. Climate, 2, 1492-1499, https://doi.org/10.1175/1520-0442(1989)002<1492: TIOSST $>2.0 . \mathrm{CO} ; 2$

Wang, M., Y. Du, B. Qiu, X. Cheng, Y. Luo, X. Chen, and M. Feng, 2017: Mechanism of seasonal eddy kinetic energy variability in the eastern equatorial Pacific Ocean. J. Geophys. Res., 122, 3240-3252, https://doi.org/10.1002/ 2017JC012711.

Wang, S., Z. Jing, H. Liu, and L. Wu, 2018: Spatial and seasonal variations of submesoscale eddies in the eastern tropical Pacific Ocean. J. Phys. Oceanogr., 48, 101-116, https://doi.org/ 10.1175/JPO-D-17-0070.1.

Wang, W., and M. J. McPhaden, 1999: The surface-layer heat balance in the equatorial Pacific Ocean. Part I: Mean seasonal cycle. J. Phys. Oceanogr., 29, 1812-1831, https://doi.org/ 10.1175/1520-0485(1999)029<1812:TSLHBI >2.0.CO;2.

Willett, C. S., R. R. Leben, and M. F. Lavin, 2006: Eddies and tropical instability waves in the eastern tropical Pacific: A review. Prog. Oceanogr., 69, 218-238, https://doi.org/10.1016/j.pocean.2006.03.010.

Wyrtki, K., 1978: Lateral oscillations of the Pacific equatorial countercurrent. J. Phys. Oceanogr., 8, 530-532, https://doi.org/ 10.1175/1520-0485(1978)008<0530:LOOTPE $>2.0 . C O ; 2$.

Xie, S. P., 1994: On the genesis of the equatorial annual cycle. J. Climate, 7, 2008-2013, https://doi.org/10.1175/1520-0442(1994) 007<2008:OTGOTE $>2.0$.CO;2.

_ 2004: The shape of continents, air-sea interaction, and the rising branch of the Hadley circulation. The Hadley Circulation: Present, Past and Future, H. F. Diaz and R. Bradley, Eds., Springer, 121-152.

— model of relevance to the ITCZ in the eastern Pacific. Tellus, 46A, 340-350, https://doi.org/10.3402/tellusa.v46i4.15484.

_ M. Ishiwatari, H. Hashizume, and K. Takeuchi, 1998: Coupled ocean-atmospheric waves on the equatorial front. Geophys. Res. Lett., 25, 3863-3866, https://doi.org/10.1029/1998GL900014.

Yu, J.-Y., and W. T. Liu, 2003: A linear relationship between ENSO intensity and tropical instability wave activity in the eastern Pacific Ocean. Geophys. Res. Lett., 30, 1735, https:// doi.org/10.1029/2003GL017176.

Yu, Z., J. P. McCreary Jr., and J. A. Proehl, 1995: Meridional asymmetry and energetics of tropical instability waves. J. Phys. Oceanogr., 25, 2997-3007, https://doi.org/10.1175/ 1520-0485(1995)025<2997:MAAEOT > 2.0.CO;2.

Zheng, S., M. Feng, Y. Du, X. Cheng, and J. Li, 2016: Annual and interannual variability of the tropical instability vortices in the equatorial eastern Pacific observed from Lagrangian surface drifters. J. Climate, 29, 9163-9177, https://doi.org/10.1175/JCLI-D-16-0124.1.

Zhou, C., and J. P. Boyd, 2009: Nonlinear shallow water tropical instability waves on the equatorial $\beta$-plane: Genesis of two distinct types of waves. Geophys. Res. Lett., 36, L23605, https://doi.org/10.1029/2009GL040499. 